\title{
Spatially resolving ocean color and sediment dispersion in river plumes, coastal systems, and continental shelf waters
}

\author{
Dirk Aurin ${ }^{\mathrm{a}, \mathrm{b}, *}$, Antonio Mannino ${ }^{\mathrm{b}}$, Bryan Franz ${ }^{\mathrm{b}}$ \\ a Science Systems and Applications, Inc., National Aeronautics and Space Administration, Goddard Space Flight Center, Code 616, Bldg. 22, Rm. 248, Greenbelt, MD 20771, USA \\ ${ }^{\mathrm{b}}$ National Aeronautics and Space Administration, Goddard Space Flight Center, Greenbelt, MD 20771, USA
}

\section{A R T I C L E I N F O}

\section{Article history:}

Received 13 March 2013

Received in revised form 14 June 2013

Accepted 23 June 2013

Available online 23 July 2013

\section{Keywords:}

Ocean color

Coastal oceanography

Satellite remote sensing

Spatial resolution

Atmospheric correction

Total suspended material

\begin{abstract}
A B S T R A C T
Satellite remote sensing of ocean color in dynamic coastal, inland, and nearshore waters is impeded by high variability in optical constituents, demands specialized atmospheric correction, and is limited by instrument sensitivity. To accurately detect dispersion of bio-optical properties, remote sensors require ample signal-to-noise ratio (SNR) to sense small variations in ocean color without saturating over bright pixels, an atmospheric correction that can accommodate significant water-leaving radiance in the near infrared (NIR), and spatial and temporal resolution that coincides with the scales of variability in the environment. Several current and historic space-borne sensors have met these requirements with success in the open ocean, but are not optimized for highly red-reflective and heterogeneous waters such as those found near river outflows or in the presence of sediment resuspension. Here we apply analytical approaches for determining optimal spatial resolution, dominant spatial scales of variability ("patches"), and proportions of patch variability that can be resolved from four river plumes around the world between 2008 and 2011. An offshore region in the Sargasso Sea is analyzed for comparison. A method is presented for processing Moderate Resolution Imaging Spectroradiometer (MODIS) Aqua and Terra imagery including cloud detection, stray light masking, faulty detector avoidance, and dynamic aerosol correction using short-wave- and near-infrared wavebands in extremely turbid regions which pose distinct optical and technical challenges. Results show that a pixel size of $\sim 520 \mathrm{~m}$ or smaller is generally required to resolve spatial heterogeneity in ocean color and total suspended materials in river plumes. Optimal pixel size increases with distance from shore to $\sim 630 \mathrm{~m}$ in nearshore regions, $\sim 750 \mathrm{~m}$ on the continental shelf, and $\sim 1350 \mathrm{~m}$ in the open ocean. Greater than $90 \%$ of the optical variability within plume regions is resolvable with 500 m resolution, and small, but significant, differences were found between peak and nadir river flow periods in terms of optimal resolution and resolvable proportion of variability.
\end{abstract}

(c) 2013 Elsevier Inc. All rights reserved.

\section{Introduction and theory}

In measuring the length of a particular stretch of convoluted coastline with many small bays and inlets, very different results are reached when measuring by the centimeter, meter, or kilometer. If the exercise were repeated at a comparatively straight and featureless coastline, these results may converge. Similarly, the composition, distribution, and diffusion of the components of seawater that give it color-chromophoric dissolved material, suspended minerals, phytoplankton, etc.-will exhibit patchiness on scales from microns to many kilometers. Any empirical approach to the question of finding the "best" resolution for ocean viewing is limited by the resolution at which observations are made. In this study, we address the issue using what is currently the most readily available, highest resolution

\footnotetext{
* Corresponding author at: Science Systems and Applications, Inc., National Aeronautics and Space Administration, Goddard Space Flight Center, Code 616, Bldg. 22, Rm. 248, Greenbelt, MD 20771, USA. Tel.: + 13012862742.

E-mail address: dirk.a.aurin@nasa.gov (D. Aurin).
}

ocean color imagery with global coverage: $250 \mathrm{~m}$ MODIS data for the $645 \mathrm{~nm}$ band. Using thousands of scenes from environments as dynamic as turbid river plumes after tropical storm flooding events to the oligotrophic Sargasso Sea, statistical and analytic tools are adapted to quantify interpixel variability from instrument noise, atmospheric correction, and ocean color itself. The spatial scales of variability ("patchiness") are identified in the process, as well as the upper limits of the pixel size required to capture dispersion of suspended sediments driving ocean color, and the degree of variability that can be resolved given these limitations.

\subsection{Background}

A recent study by Lee, Hu, Arnone, and Liu (2012) demonstrated that satellite ocean color products derived from low resolution imagery are not necessarily the arithmetic or geometric average of those derived from high resolution imagery over the same scene. As a result, low resolution imagery in environments with steep gradients such as eddies, fronts, phytoplankton blooms, and river plumes can 
underestimate the concentration of retrieved optical properties and biogeochemical constituents. Using comparisons of the absorption coefficient retrieved from high resolution $(300 \mathrm{~m})$ and low resolution $(1.2 \mathrm{~km}$ ) Medium Resolution Imaging Spectrometer (MERIS) imagery over a large $\left(\sim 21,800 \mathrm{~km}^{2}\right)$ eddy in the Southern Ocean, they found that absorption was underestimated in the low resolution product by $\sim 5-15 \%$-particularly along the strongest spatial gradients in the absorption coefficient. By extension, they conclude that global estimates of satellite-retrieved products (i.e. chlorophyll concentration, Chl) have historically been underestimated due to the relatively coarse resolution of the current suite of satellite sensors.

Patchiness in optical constituents of the ocean is present at all spatial scales. Physical and biological oceanographic processes also occur at spatial scales from sub-millimeter to thousands of kilometers (e.g. Fig. 6 in (Dickey, Lewis, \& Chang, 2006)). Regions with strong gradients in Chl-such as a bloom-or total suspended material (TSM)-such as a river plume-will be inherently patchier than oligotrophic, low mineral content waters far from shore. The design of remote sensing satellites must be sensitive to the spatial scales of constituent variability in order to accurately assess their concentration and distribution. As an example, in planning for the GEOstationary Coastal and Air Pollution Events satellite (GEO-CAPE) (Fishman et al., 2012), the technological, financial, and logistical costs of building a high spatial resolution sensor must be balanced against its capability to resolve natural variability and uncertainties in products retrieved in patchy environments. Nevertheless, high resolution (e.g. $<1 \mathrm{~km}$ ) may not be necessary for large areas of open ocean. Addressing the ocean science questions for GEO-CAPE (http://geo-cape.larc.nasa. gov/ocean.html) is a particular challenge with respect to spatial resolution because its high geostationary orbit $(35,786 \mathrm{~km}$ altitude over $\sim 95^{\circ} \mathrm{W}$ ) will require a more massive telescope and longer "stare interval" for any given target, which in turn limits coverage. Estimating spatial resolution requirements for various environments from dynamic river plumes to the open ocean-as we endeavor to do here-can facilitate optimizing the revisit time over each target area, thereby increasing temporal resolution as well as spatial coverage.

\subsection{Tools for assessing GSD}

The optimal ground space distance (GSD) is the spatial resolution below which spatial heterogeneity in ocean color-or the underlying bio-optical constituents such as Chl or TSM-cannot be resolved. Theoretically, this decreases from quiescent regions offshore to coastal environments and turbid river plume regions. The latter regions are characterized by strong seasonal and episodic influx of TSM (mainly non-algal sediments), and present the additional challenge of being environments in which standard approaches to satellite imagery processing are often inadequate (Ruddick, Ovidio, \& Rijkeboer, 2000).

Ideally, any interpixel variability of adjacent pixels in ocean color products represents real differences in constituent concentrations. In such a case, finding the GSD for a given region would be a straightforward matter of reducing spatial resolution in an image (i.e. increasing GSD by averaging adjacent pixels) until variability in adjacent pixels is no longer negligible, beyond which the capacity for gauging dispersion in the constituent concentration is reduced. For example, if variability of adjacent pixels is significant among $250 \mathrm{~m}$ pixels, then larger pixels (e.g. $500 \mathrm{~m}$ ) would overlook these differences. In fact, some of the interpixel variability in satellite images derives from non-geophysical influences such as the signal to noise ratio (SNR) of the satellite detector, artifacts arising from processing the image for atmospheric correction, and uncertainties in the algorithm used to retrieve the biogeochemical constituents from above water reflectances. Therefore, in order to determine optimal GSD in naturally noisy imagery, a threshold of noise above which differences in interpixel variability result from true differences in ocean color must be determined. To eliminate the complication of uncertainties introduced by ocean color algorithms, we generally limit our analysis here to the ocean color signal itself. Specifically, we will focus on the remote sensing reflectance at $645 \mathrm{~nm}, R_{r s}(645)$. This waveband was chosen for three reasons, 1 ) it is available on both MODIS Aqua and Terra instruments and therefore has readily accessible global coverage together with up-todate calibration and on-orbit signal-to-noise information, 2) it is measured at relatively high resolution $(250 \mathrm{~m})$, and 3 ) it is an excellent proxy for TSM (e.g. (Kirk, 1994; Miller \& McKee, 2004; Ondrusek et al., 2012)) although regional optimization is generally required in MODIS band 1 ( $645 \mathrm{~nm}$ ) algorithms for TSM as absorption features such as Chromophoric Dissolved Organic Material (CDOM) and phytoplankton pigments chlorophyll a and phycocyanin can significantly impact sea surface reflectance in this band. The $645 \mathrm{~nm}$ band in MODIS was originally designed as a land band, and therefore has a much lower SNR than the MODIS ocean bands ( $160.5 \pm 7.2$ at typical $645 \mathrm{~nm}$ oceanic radiance of $1.72 \pm 0.21 \mathrm{mWcm}^{-2} \mu \mathrm{m}^{-1} \mathrm{sr}^{-1}$ versus 2000 in ocean bands (Hu et al., 2012)). As we demonstrate in our results below, this introduces significant noise in band 1 offshore, but in turbid, highly reflective river plumes such as those studied here, radiances are often five times greater, thereby boosting SNR to $\sim 500$ or higher. The $645 \mathrm{~nm}$ band on MODIS is also quite broad at $\sim 50 \mathrm{~nm}$, but this should not impact interpixel variability for the purpose of GSD evaluation, nor is it likely to significantly impact its utility in deriving TSM since ocean color in this region of the spectrum is dominated by scattering-i.e. the single scattering albedo (the ratio of scattering to total attenuation) approaches 1 in most environments (Babin, Morel, Fournier-Sicre, Fell, \& Stramski, 2003).

Bissett et al. (2004) studied the issue of optimal GSD using aircraft imagery collected over the LEO-15 study site off New Jersey and found the random noise component of the surface reflectance signal by calculating the standard deviation between adjacent pixels in a region within the image known to be relatively homogeneous in its water-borne optical properties, using this observed variability over a quiescent region as their threshold $\left(\sigma_{\mathrm{t}}\right)$. Assuming the noise to be linearly additive (constant, regardless of the magnitude of the signal), a transect of virtual stations was mapped onto the image in a nearby region in which optimal GSD was sought. At each station, an analysis was conducted in which the interpixel variability of pixels immediately adjacent to the station is calculated (i.e. the standard deviation of a $3 \times 3$ array of pixels centered on the ith station, $\sigma_{\mathrm{i}}$ ). If $\sigma_{\mathrm{i}}$ was higher than the threshold of random noise, $\sigma_{t}$, then it was determined that true differences existed in the optical properties of the water column between these adjacent pixels, and a coarser GSD would miss this variability. If not, the array was increased to $5 \times 5,7 \times 7$, etc. until that condition was met. The resolution of the last aggregate array for which $\sigma_{\mathrm{i}} \leq \sigma_{\mathrm{t}}$ determined the optimal resolution, or GSD. Based on a virtual transect superimposed on a single aircraft image collected by the PHILLS 2 instrument at $9 \mathrm{~m}$ resolution at the LEO-15 study site, they found that near shore $(<10 \mathrm{~km}$ from the coast) the optimal GSD was $\sim 100-200 \mathrm{~m}$, and increased to $\sim 2000$ $6000 \mathrm{~m}$ between 10 and $50 \mathrm{~km}$ from shore.

Here we pursue an approach similar to Bissett et al. (2004), but expand it to include thousands of satellite images collected over several optically diverse regions and seasons. For practical reasons described in more detail below, the methods are modified in our analysis to accommodate the use of MODIS Aqua and Terra satellite imagery. Rather than using an optically quiet region of an image to estimate $\sigma_{\mathrm{t}}-\mathrm{as}$ in (Bissett et al., 2004)-in this investigation, the noise threshold is determined explicitly by combining on-orbit SNR for the MODIS band 1 with noise introduced by atmospheric correction. The optimal GSD in this study is established as the average between the size of the last pixel array for which interpixel variability is within the noise $\left(\sigma_{i} \leq \sigma_{t}\right)$ and the size of the first pixel array for which variability exceeds the noise threshold $\left(\sigma_{\mathrm{i}}>\sigma_{\mathrm{t}}\right)$. A limitation in using MODIS QKM (nominally $250 \mathrm{~m}$ ) imagery is that it cannot extend to resolutions lower than the smallest aggregation of pixels-a $2 \times 2$ array-or an optimal GSD of $375 \mathrm{~m}$. In other words, recommendations made here regarding regions with the most stringent GSD requirements (i.e. plume regions) are 
typically upper limits of pixel size, but both upper and lower bounds may apply nearshore, on the shelf, or offshore where ranges of optimal GSD are well above the $375 \mathrm{~m}$ limit.

A statistical method often used to describe spatial variability in environmental measurements is the semivariogram which builds on the intuitive premise that closer observations have a higher probability of being similar than distant observations. The shape of semivariance $(\gamma)$ with distance (or "lag" $h$, see Fig. 1 ) has been used to describe geographical patterns in the marine environment such as chlorophyll variability in the oceans (Doney, Glover, McCue, \& Fuentes, 2003), to help establish spatial scales of variability in remotely sensed parameters, and to describe the proportion of variability captured at a given resolution (Atkinson \& Curran, 1997; Davis, Kavanaugh, Letelier, Bissett, \& Kohler, 2007).

The semivariance function is found by calculating half the squared difference of all pixel pairs in an image at distance $h$ from each other in any direction, over all possible distances. The example semivariogram in Fig. 1 shows idealized models for $\gamma(h)$ with descriptive characteristics. As distance $h$ increases to the range, the semivariance first increases as more distant observations become less similar, and then plateaus at the sill-the distance at which differences between observations are no longer a function of distance, but rather reflect the overall variability in the region (or sub-regional patch) being evaluated. The smallest distance in a satellite image is the same as the pixel size, so the nugget (i.e. the semivariance approaching the y-intercept) reflects the unresolved variability at a given resolution. The rate at which $\gamma$ rises to reach the sill (the shape of the curves in Fig. 1) can be viewed as an indication of intermediate scale patchiness, and nodes-deviations from the smooth, approximately hyperbolic slope-indicate spatial scales at which patchiness is a factor. Multiple sills may exist in a semivariogram which encompasses diversity at different spatial scales (e.g. dotdashed line in Fig. 1). Typically, semivariograms assume an isotropic distribution of observations, so strong spatial gradients may distort results. If a gradient is known to exist a priori, it is also possible to calculate the non-isotropic semivariance; the semivariance along a particular direction believed to be free from significant, systematic gradients. Semivariograms are used in this study assuming isotropy within the smallest patches observed (typically $20-100 \mathrm{~km}$ )-and only within the plume regions-to establish spatial scales of patchiness, overall variability of a region, and the degree of variability captured by various resolutions of satellite imagery, while avoiding the strong gradient between the plume and open ocean waters which could distort results.

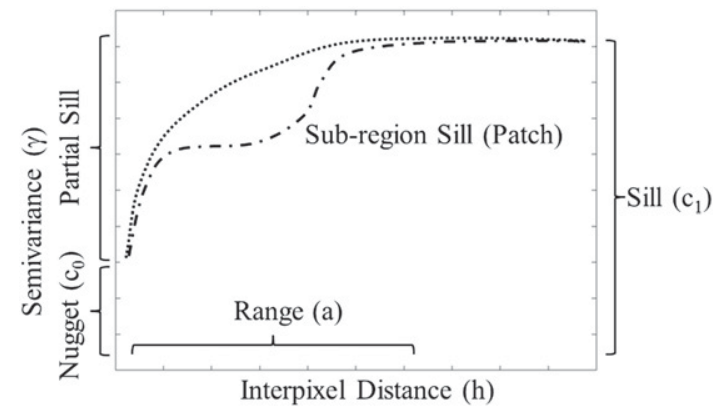

Fig. 1. Idealized semivariograms (dotted and dash-dotted lines) demonstrate spatial variability in nature tending to increase with distance between observations. The sill $\left(c_{1}\right)$ represents the total scale of variability of a region at a distance equal to the range (a) where variance plateaus. Increasing the size of the region to incorporate diversity not previously encompassed may cause variance to rise above one sill until a new sill is reached (dash-dotted line), demonstrating spatial scales of "patchiness". If the semivariance is scaled to the sill in a given region, the partial sill $\left(=1-\right.$ nugget $\left.\left(c_{0}\right)\right)$ is the proportion of variability that can be resolved as the distance approaches the $y$-intercept. This distance is equivalent to the minimum distance possible in a satellite image (i.e. the pixel size or resolution).

\subsection{Uncertainty in surface reflectance}

The ability to determine optimal GSD from satellite imagery depends on establishing the interpixel variability in the reflectance signal above the variability caused by signal uncertainty or noise (i.e. $\sigma_{\mathrm{i}}>\sigma_{\mathrm{t}}$, where $\sigma$ is the standard deviation of an array of pixels divided by the average: the coefficient of variability). For the spectral remote sensing reflectance $\left(R_{r s}(\lambda)\right.$; the water-leaving radiance scaled to the surface downwelling irradiance), uncertainty $(\Delta)$ can be expressed by propagation of error as:

$\Delta R_{r s}(\lambda)=\frac{L_{w}(\lambda)}{E_{d}(\lambda)} \sqrt{\left(\frac{\Delta L_{w}(\lambda)}{\Delta E_{d}(\lambda)}\right)^{2}+\left(\frac{\Delta E_{d}(\lambda)}{E_{d}(\lambda)}\right)^{2}}$,

where $L_{w}(\lambda)$ is the spectral water-leaving radiance, $E_{d}(\lambda)$ is the spectral sea-surface irradiance, and $\lambda$ is wavelength (spectral notation suppressed for brevity hereafter). Top of atmosphere radiance is the sum of radiance contributions from aerosols $L_{a}$, glint $L_{g}$, combined Rayleigh correction and Rayleigh-aerosol interactions $L_{r a}$, white-caps $L_{w c}$, and $L_{w}$. Including the uncertainty in each of these elements as well as the atmospheric transmittance coefficient $t$ yields:

$L_{t} \pm \Delta L_{t}=L_{a} \pm \Delta L_{a}+L_{g} \pm \Delta L_{g}+L_{r a} \pm \Delta L_{r a}+L_{w c} \pm \Delta L_{w c}+t\left(L_{w} \pm \Delta L_{w}\right)$,

and again by propagation of error,

$\Delta L_{t}=\frac{\sqrt{\Delta L_{t}^{2}-\Delta L_{a}^{2}-\Delta L_{g}^{2}-\Delta L_{r a}^{2}-\Delta L_{w c}^{2}}}{t}$

Combining Eqs. (1) and (2) yields total uncertainty in $R_{r s}$ :

$\Delta R_{r s}=R_{r s} \sqrt{\frac{\Delta L_{t}^{2}-\Delta L_{a}^{2}-\Delta L_{g}^{2}-\Delta L_{r a}^{2}-\Delta L_{w c}^{2}}{\left(t L_{W}\right)^{2}}+\left(\frac{\Delta E_{d}}{E_{d}}\right)^{2}}$.

Given that the $645 \mathrm{~nm}$ MODIS band was designed for land use, its SNR ratio over water will be a major source of uncertainty, particularly in low turbidity pixels throughout our regions. Furthermore, as described in Section 2.1.5, atmospheric correction methods will depend on both near infra-red (NIR) and short-wave infrared (SWIR; $1240 \mathrm{~nm}$ and $2130 \mathrm{~nm}$ for MODIS) bands. Due in large part to the low SNR in the SWIR bands ( $48.4 \pm 3.9$ and $30.8 \pm 3.3$, respectively (Hu et al., 2012)), atmospheric correction is likely to be another major source of uncertainty. Isolating the uncertainty in $L_{t}$ driven by instrument noise from the remaining atmospheric correction terms in Eq. (3) yields

$\Delta R_{r s}=\Delta R_{r s}^{L t}+\Delta R_{r s}^{A C}$,

where $\Delta R_{r s}^{L t}$ is uncertainty owing to the SNR in $L_{t}$, and $\Delta R_{r s}^{A C}$ is uncertainty in the atmospheric correction.

If uncertainty in $R_{r s}$ were solely due to instrument noise in the TOA radiance, where $\Delta L_{t}=L_{t} / S N R_{L t}$, and $S N R_{L t}$ is the signal to noise ratio in $L_{t}$, Eq. (3) reduces to:

$\Delta R_{r s}^{L t}=R_{r s} \frac{L_{t}}{t L_{w} S N R_{L t}}$.

However, atmospheric correction (i.e. the remaining terms in Eq. (3)) introduces large uncertainty near shore and in turbid waters. Uncertainty in ocean color products deriving from atmospheric correction, including the SNR in NIR and SWIR bands, was estimated by the Pre-Aerosol, Clouds, and ocean Ecosystem (PACE) Science Definition Team in their report in October 2012 (http://decadal.gsfc.nasa.gov/pace.html). Interpolating between the $555 \mathrm{~nm}$ and $670 \mathrm{~nm}$ bands in that study (see their Fig. A-1), conservatively estimating SNR in NIR and SWIR bands from MODIS ( $~ 800$ and $\sim 50$, respectively (Hu et al., 2012)), and 
converting to error in $R_{r s}$ from normalized water leaving radiance yields uncertainty in the $645 \mathrm{~nm}$ of approximately $\Delta R_{r s}^{A C}=6.4 \times 10^{-5} \mathrm{sr}^{-1}$ when NIR bands are used for atmospheric correction, and $\Delta R_{r s}^{A C}=$ $8.0 \times 10^{-4} \mathrm{sr}^{-1}$ when SWIR bands are used.

From Eqs. (4) and (5), and a pixel-by-pixel assessment of which bands were used for atmospheric correction (Section 2.1.5), we estimate the non-biogeochemical variability in sea surface reflectance $\left(\sigma_{t}\right)$ on a pixel-by-pixel basis for all images studied.

\section{Data, areas of interest, and methodology}

Prior studies of spatial resolution such as those mentioned above have focused on models and/or small sample sizes of imagery (Atkinson \& Curran, 1997; Bissett et al., 2004; Davis et al., 2007; Lee et al., 2012; Ruddick et al., 2012). Our goal is to adapt and generalize these approaches to cover plumes of major and minor rivers, nearby estuarine, coastal, and shelf waters, and regions far from land.

\subsection{Satellite imagery}

3076 MODIS level 1A (L1A) Aqua and Terra granules collected during peak and nadir flow periods over major river outflows (Amazon, Mississippi, Susquehanna, and Yangtze Rivers) between 2008 and
2011 were downloaded from NASA's archive (http://oceancolor.gsfc. nasa.gov) and regionally extracted and processed using the SeaWiFS Data Analysis System (SeaDAS 6.4) to level 2 (L2) using a novel methodology optimized for highly turbid zones, as described in Section 2.1.5 and Fig. 3. In addition, 1104 L1A images from an optically quiescent region in the Sargasso Sea bounded by $25^{\circ} \mathrm{N}$ and $35^{\circ} \mathrm{N}$ latitude and $-45^{\circ} \mathrm{W}$ and $-55^{\circ} \mathrm{W}$ longitude during May and November 2008-2011 were processed to L2 using standard operational methods for ocean color (Ahmad et al., 2010; Bailey, Franz, \& Werdell, 2010; Gordon \& Wang, 1994) L2 images were generated at $1000 \mathrm{~m}$ resolution (1KM), $500 \mathrm{~m}$ resolution (HKM) and $250 \mathrm{~m}$ resolution (QKM), which is the native, nadir, nominal resolution for the $645 \mathrm{~nm}$ band (band 1, MODIS) used here as an analog to TSM. Actual spatial resolution is a function of satellite viewing geometry, and is calculated for each image prior to GSD and semivariance analysis. QKM scenes with $>500$ m native resolution are rejected from analysis.

Regions of interest are shown in greater detail in Fig. 2 together with example retrievals of $R_{r S}(645)$ determined using the methods described below (Section 2.1.5). Sub-regions (plume, coastal/estuary/ nearshore, and continental shelf waters; black, red, and green boxes, respectively) are delineated in the figure, and the virtual transects and stations used in the analysis of optimal GSD in each sub-region are superimposed. Qualitative selection of sub-regions was based
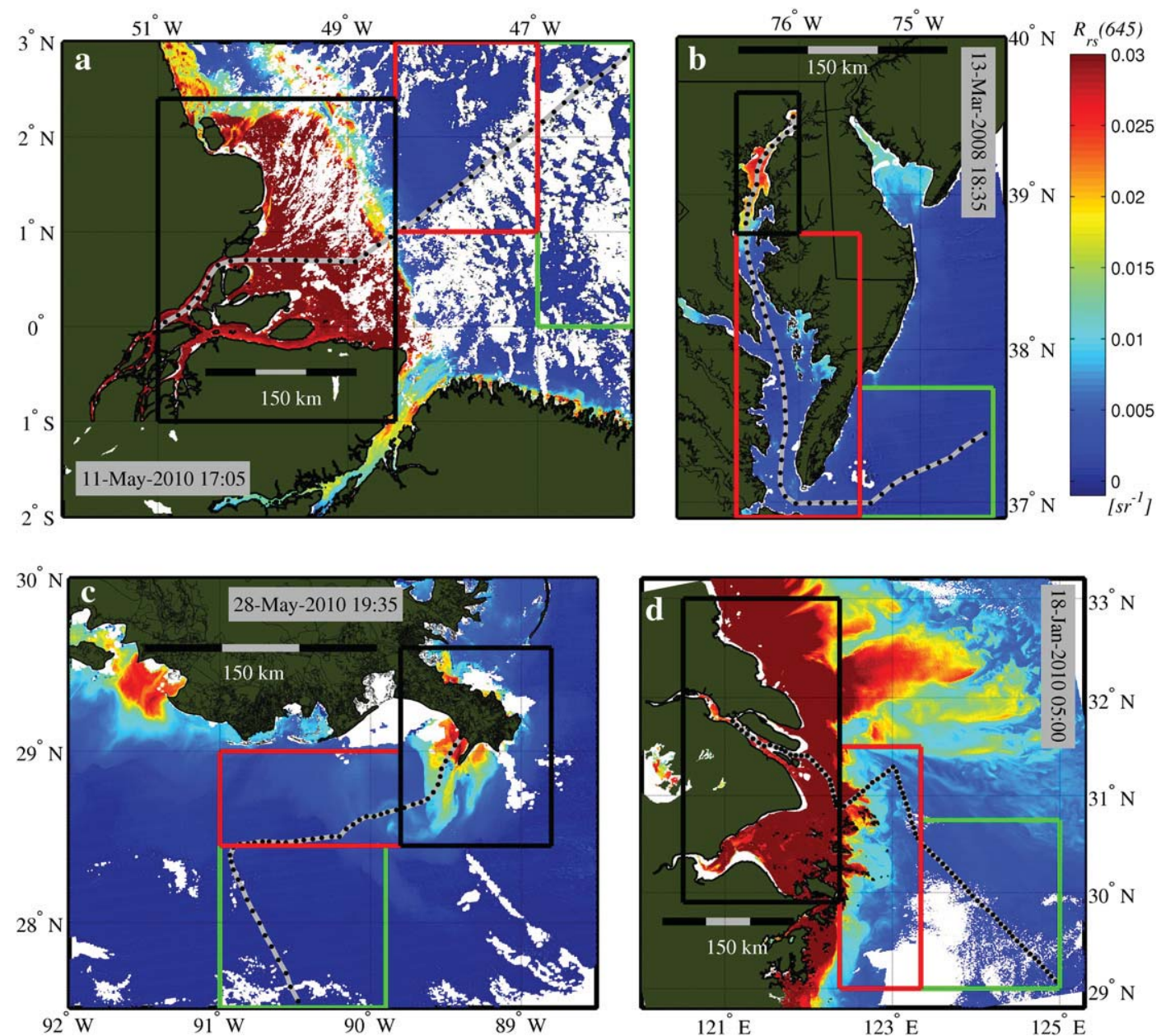

Fig. 2. MODIS $R_{r s}(645)$ (derived using the methodology developed in Section 2.1.5) in our four river plume regions of interest during heavy outflow (a) Amazon River, b) Chesapeake Bay, c) Mississippi River, 4) Yangtze River). Sub-regions include the plume waters (black box), estuarine/near-shore/coastal waters (red box), and shelf waters (green box). Virtual transects designed for GSD analysis are shown in gray with stations (points) denoted. Each plot shows the date and time of MODIS acquisition and scale. White areas over water are masked for clouds and stray light around clouds and land. 
on visual inspection of satellite imagery for $R_{r s}(645)$. Specifically, seaward boundaries of typical plume fronts were used to define the plume, while the coastal sub-regions were situated in areas found to dynamically shift between turbid and clear waters, and continental shelf waters were comparatively quiescent and dark at $645 \mathrm{~nm}$.

\subsubsection{Amazon River}

The Amazon River drains a region of South America over $6 \times 10^{6} \mathrm{~km}^{2}$ and has the highest discharge of any river in the world, with flow rates between $7.5 \times 10^{4}$ and $3.8 \times 10^{5} \mathrm{~m}^{3} \mathrm{~s}^{-1}$ and an average discharge of $2.09 \times 10^{5} \mathrm{~m}^{3} \mathrm{~s}^{-1}$ (Guyot, Callede, Molinier, Guimaraes, \& Oliveira, 1997; Moreira-Turcq, Seyler, Guyot, \& Etcheber, 2003) with which it delivers $3.27 \times 10^{13} \mathrm{~g} \mathrm{C} \mathrm{yr}^{-1}$ into the Atlantic Ocean. TSM is high throughout the Amazon River network, with some regions reaching values over $300 \mathrm{mg} \mathrm{l}^{-1}$ (Moreira-Turcq et al., 2003). Flow is seasonally tied to rain fall, reaching average peak flow in May, and nadir flow in November (Zeng, 1999), and is strongly linked to E1 Niño-Southern Oscillation (ENSO) (Molinier et al., 2009). The plume of the Amazon River extends several hundred kilometers seaward, and-like many tropical regions-is characterized by frequent, heavy cloud cover. Hu, Montgomery, Schmitt, and Muller-Karger (2004) studied the plume further from shore between 1997-2002 using concurrent SeaWiFS satellite ocean color and in situ observations, and found that patches of fresher, CDOM-dominated waters originating from the Amazon and Orinoco extended as far as $2000 \mathrm{~km}$ to the north and west of the Amazon mouth. Large (400-500 km) eddies were observed moving northward from the plume along the coast at a frequency of about 1-2 months in all seasons. The North Brazil Current and the North Equatorial Counter Current carried colored waters from the plume $>3000 \mathrm{~km}$ into the tropical Atlantic in 1998. Plume areal extent between 2000 and 2004 mapped by correlating the SeaWiFS-derived detrital and dissolved absorption coefficient to sea-surface salinity ranged from $268 \times 10^{3} \mathrm{~km}^{2}$ to $1506 \times 10^{3} \mathrm{~km}^{2}$ (Molleri, Novo, \& Kampel, 2010).

713 MODIS Aqua and Terra scenes covering the Amazon plume were selected during May and November 2008 (La Nina; peak rains), 2009, 2010 (El Nino; less rain), and 2011 (La Nina; http:// www.cpc.noaa.gov/products/analysis_monitoring/lanina/ enso_evolution-status-fcsts-web.pdf).

\subsubsection{Chesapeake Bay}

Located in the eastern United States and draining an area of about $1.65 \times 10^{5} \mathrm{~km}^{2}$, the Chesapeake Bay receives the majority of its fresh water and nutrient loading from the Susquehanna River (average discharge $1.06 \times 10^{3} \mathrm{~m}^{3} \mathrm{~s}^{-1}$ (Gellis, Banks, Langland, \& Martucci, 2005)) at the head of the Bay (Harding, Itsweire, \& Esaias, 1994). Sediment loading combined with high concentrations of CDOM from the Susquehanna and other tributaries lead to diffuse attenuation of light in the water column, $K_{d}(490)$, as high as $\sim 10 \mathrm{~m}^{-1}$ (Wang, Son, \& Harding, 2009), which in turn degrades benthic habitat critical to local fisheries. TSM concentrations of 10-50 $\mathrm{mg} \mathrm{l}^{-1}$ are not uncommon at the head of the Bay, but are generally $<10 \mathrm{mg} \mathrm{l^{-1 }}$ in the central and lower Bay (Ondrusek et al., 2012).

The use of a specialized atmospheric correction for turbid waters using both SWIR and NIR bands for aerosol correction has yielded encouraging results in the Chesapeake Bay for retrieving $K_{d}(490)$ (Wang et al., 2009). However, an evaluation of the method for SWIR aerosol correction as implemented in SeaDAS software was criticized in (Werdell, Franz, \& Bailey, 2010) for yielding a much larger range of variability and higher frequency of negative water leaving radiance retrievals; results consistent with increased SWIR atmospheric correction noise as discussed in Section 1.3.

630 MODIS images were selected from average peak (March) and nadir (September) flow periods between 2008 and 2011 based on United States Geological Survey (USGS) river gauge data collected at the Conowingo Dam (http://waterdata.usgs.gov/usa/nwis/uv?01578310).

\subsubsection{Mississippi River}

The Mississippi River drains $41 \%$ of the continental United States $\left(3.27 \times 10^{6} \mathrm{~km}^{2}\right)$ with an annual discharge rate of $1.84 \times 10^{4} \mathrm{~m}^{3} \mathrm{~s}^{-1}$ and averages a flow rate of $1.35 \pm 0.2 \times 10^{4} \mathrm{~m}^{3} \mathrm{~s}^{-1}$ (Milliman \& Meade, 1983). Plume waters measured from satellite have been shown to reach as far as the Gulf Stream (Hu et al., 2005), and the plume extent (TSM $>5 \mathrm{mg} \mathrm{l}^{-1}$ ) following a flooding event in 2008 was estimated from satellite to be as high as $5859 \mathrm{~km}^{2}$, or about double that of the climatological average (2002-2008) (Shi \& Wang, 2009b). The estimated $2.1 \times 10^{8}$ tons (Milliman \& Meade, 1983) of sediment delivered by this flow to the shelf annually are accompanied by high inorganic nutrient loading contributing to recurrent hypoxia in the bottom waters of the shelf (Rabalais et al., 1996). Average peak and nadir flow periods for our study period were May and September, respectively, based on USGS gauge data (http://waterdata.usgs.gov/usa/nwis/uv? site_no=07374000). 803 MODIS images were selected from the Mississippi region in the period between 2008 and 2011.

\subsubsection{Yangtze River}

The Yangtze River drains about $1.94 \times 10^{6} \mathrm{~km}^{2}$ and has an annual discharge of $2.85 \times 10^{4} \mathrm{~m}^{3} \mathrm{~s}^{-1}$ (Milliman \& Meade, 1983) making it the fourth largest in the world. While suspended sediment delivery to the shelf $\left(\sim 5.0 \times 10^{8}\right.$ tons annually $)$ is principally controlled by river flow (average $3.0 \times 10^{5} \mathrm{~m}^{3} \mathrm{~s}^{-1}$ ), spring and neap tides play a significant role (Milliman, Huang-ting, Zuo-sheng, \& Mead, 1985). Seasonal river flows and sediment discharges peak in July with the Southeast Asian summer monsoon, and are generally near nadir in January (Beardsley, Limeburner, Yu, \& Cannon, 1985) when prevailing winds turn offshore. Surface turbidity as measured by $K_{d}(490)$ estimates from MODIS have a nearly opposite pattern on the nearby shallow shelf owing to high winter winds and a breakdown in stratification leading to resuspended particles mixing to the surface (Shi \& Wang, 2010).

The plume of the Yangtze is defined here to include the Hangzhou Bay at the mouth of river, as well as adjacent shallow ( 20 m) shoreline regions where turbidity is driven by a combination of these factors (Fig. 2). 757 MODIS images were selected from the region during January and July 2008-2011.

\subsubsection{Atmospheric correction and quality assurance}

SeaDAS software (http://seadas.gsfc.nasa.gov/) provides a reliable, user-friendly interface for atmospherically correcting ocean color data from several instruments over the vast majority of the world's oceans. However, several challenges must be overcome in order to accurately process MODIS ocean color imagery in highly turbid zones-the most significant being the atmospheric correction. Traditionally, visible (VIS, $400 \mathrm{~nm}-700 \mathrm{~nm}$ ) bands are atmospherically corrected using two bands in the NIR (748 nm (band 15, $10 \mathrm{~nm}$ bandwidth) and $869 \mathrm{~nm}$ (band $16,15 \mathrm{~nm}$ bandwidth) for MODIS) to remove contributions to the TOA reflectances attributable to aerosols. Standard atmospheric correction algorithms for the global oceans assume negligible water leaving radiance in the NIR due to the strong absorption coefficient for water in this region of the spectrum (the "black pixel" assumption (Gordon \& Wang, 1994)). More recently, this approach has been refined in SeaDAS to include an iterative correction with a bio-optical model for estimating $L_{w}$ (NIR) (Bailey et al., 2010). However, in highly turbid coastal waters, strong particulate backscattering often leads to relatively high $L_{w}(N I R)$, thereby violating the NIR black pixel assumption, and often leading to non-convergence of the iterative bio-optical optimization in extreme conditions, as we show below. Furthermore, NIR bands on MODIS sensors Aqua and Terra both saturate at TOA radiances above $\sim 2.8-3.45 \mathrm{~mW} \mathrm{~cm}^{-2} \mu \mathrm{m}^{-1} \mathrm{sr}^{-1}$ (748 nm) and $\sim 1.9-2.45 \mathrm{~mW} \mathrm{~cm}{ }^{-2} \mu \mathrm{m}^{-1} \mathrm{sr}^{-1}$ (869 nm), which leads to data dropouts over the most reflective plume regions (> 30-35 $\mathrm{mg} \mathrm{l}^{-1}$ TSM).

The default cloud mask in SeaDAS also depends on cloud albedo in the $869 \mathrm{~nm}$ band, and even in areas where it is not saturated, the default threshold for cloud identification (cloud albedo $>0.027$ ) is 
subject to significant error due to non-negligible water leaving radiance at $869 \mathrm{~nm}$ in turbid waters (Wang \& Shi, 2006).

A method for avoiding violation of the NIR black pixel assumption has been developed which utilizes MODIS bands in the SWIR (1240 nm (band 5, $20 \mathrm{~nm}$ bandwidth) and $2130 \mathrm{~nm}$ (band 7, $50 \mathrm{~nm}$ bandwidth) in MODIS) (Wang, Son, \& Shi, 2010). At the longer of these two wavelengths, water leaving radiance is effectively zero even in highly turbid waters because the absorption coefficient for water in the SWIR is more than two orders of magnitude higher than in the NIR (Shi \& Wang, 2009a). Unfortunately, the standard application of this atmospheric correction in SeaDAS requires the use of the NIR bands (as well as additional requirements on Chl and $n L_{w}$ ) to establish a turbidity index above which the SWIR correction is applied, and in highly turbid waters such as those often found in our areas of interest, these bands are saturated. To further complicate matters, the $1240 \mathrm{~nm}$ channels in both the Aqua and Terra instruments-originally designed for land applications-have low SNR as well as malfunctioning detectors, leading to increased noise and missing data in the final, atmospherically corrected L2 product. The $2130 \mathrm{~nm}$ channel on Terra is also subject to data dropouts due to an instrument crosstalk issue.

Other challenges to processing MODIS imagery in highly turbid waters include the default masks in SeaDAS L2 file generation scripting (the 12gen module) for high light and stray light. Stray light is light reflected into the detector from nearby bright land or cloud pixels. These masks often hide proportionately large and sometimes critical areas of nearshore, estuarine, lake, and inland waters. High light masking is based on saturation or near-saturation in the MODIS NIR bands, and therefore cannot be used in highly turbid environments (i.e. they may saturate before other sensors/bands of interest). No stray light correction is currently attempted in SeaDAS for MODIS. Stray light masking-while not active by default-is nevertheless important for eliminating light contamination in pixels adjacent to bright targets. When activated, the default mask of 5 along-track pixels by 7 across-track pixels around bright land and cloud/ice pixels can significantly reduce data coverage, and may be impractical in nearshore, estuarine, and inland waters.
Experimentation with various atmospheric correction and masking permutations guided us in our approach to MODIS L2 file generation in SeaDAS for our river plume regions of interest. $R_{r s}$ products from each method were evaluated for signal contamination (e.g. excessive stray light and other artifacts resulting from inadequate masking), poor atmospheric correction (e.g. high frequency of negative or otherwise unrealistic reflectances), and poor retrieval (e.g. discontinuities and values outside of the range of field measurements found in the literature). It should be noted that no comprehensive, quantitative validation of $R_{r s}$ retrievals is attempted here. We insure a continuous transition in each scene between products derived using standard methods in darker offshore waters (as described above and in (Bailey et al., 2010; Gordon \& Wang, 1994)) and those derived using methods optimized for turbid pixels (described below). Furthermore, we compare retrievals of TSM using our methodology to field measurements for one particular example in the Chesapeake Bay following major flooding caused by Hurricane Irene and Tropical Storm Lee in 2011. The primary goal of this study-evaluating optimal GSD in ocean color imagery-depends principally on the interpixel variability in ocean color products rather than their absolute magnitude. Nevertheless, qualitative and quantitative steps are described below which insure that retrievals of $R_{r s}$ are within reasonable ranges.

The first processing step (see Fig. 3 for a processing flow-chart) was to estimate $R_{r s}(645)$ for each scene with a methodology optimized for high turbidity pixels (hereafter referred to as HT). Unix shell batch scripts called the SeaDAS 6.4 subroutine 12gen, forcing the use the SWIR aerosol correction (i.e. parameter options aer_opt $=-1$, aer_wave_short $=$ 1240, aer_wave_long $=2130$ ). To mitigate data loss due to bad detectors and crosstalk issues in the SWIR bands, and to reduce the impact of low SNR in these bands, the 1240 and 2130 bands were smoothed by a $3 \times 3$ pixel filter prior to atmospheric correction. This is accomplished by defining a custom msl12_filter.dat parameter file (found in the SeaDAS \$OCDATAROOT directory) and adding lines for bands 14 and 16 (i.e. ltmean, 14, 3, 3, 1; ltmean 16, 3, 3, 1). High light masks were disabled, and stray light masks were set to a $3 \times 3$ array around land and clouds (i.e. maskland $=1$, maskhilt $=0$, maskstlight $=1$, maskcloud $=1$,

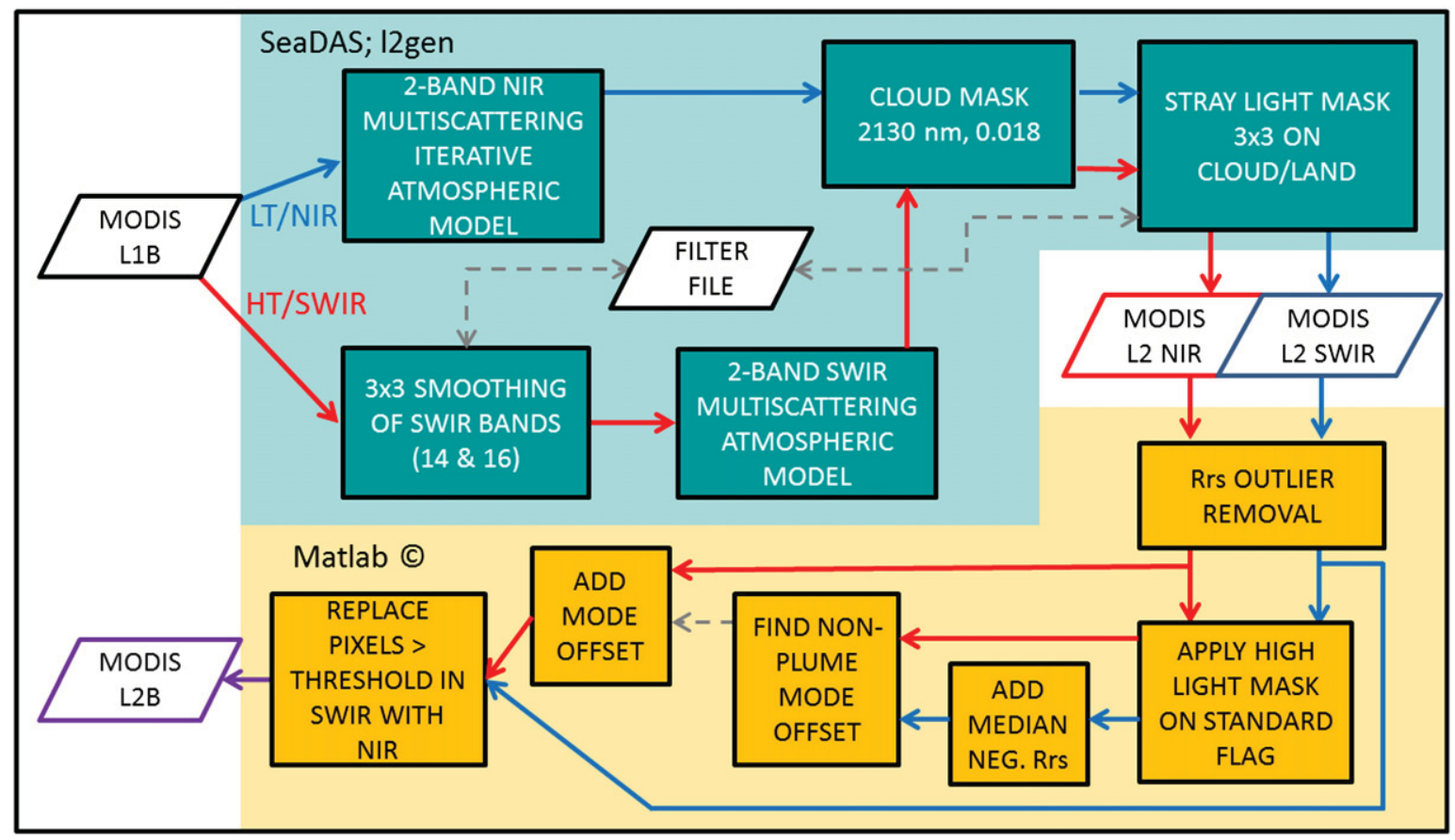

Fig. 3. Processing flowchart for deriving a blended satellite product using a method optimized for high turbidity (HT) pixels and SWIR aerosol model selection as well as low turbidity pixels (LT) and bio-optical iteration of the NIR aerosol model selection as described in Section 2.1.5. Shaded regions indicate software used during process flow (i.e. SeaDAS and Matlab). 
filter_file $=$ \$OCDATAROOT/modisa/msl12_filter_custom.dat in the scripted call to l2gen, and stlight, 10, 3, 3, 1 in the custom filter file). The $2130 \mathrm{~nm}$ SWIR band was used to mask clouds with a threshold albedo of $>0.018$ (cloud_thresh $=0.018$ ). Unrealistic $R_{r S}(645)$ retrievals $\left(R_{r s}(645)<=-0.02 \mathrm{sr}^{-1}\right.$ or $\left.R_{r s}(645)>0.12 \mathrm{sr}^{-1}\right)$ were discarded. Scenes with $>85 \%$ cloud cover were also discarded as they have the potential to introduce excessive noise due to cloud shadow and error in cloud masking. The remaining scenes were output at QKM, HKM, and $1 \mathrm{KM}$ resolution, the latter two of which are derived from native resolution in SeaDAS using pixel aggregation and averaging (http://mcst.gsfc.nasa. gov/sites/mcst.gsfc/files/file_attachments/M1054.pdf).

For darker waters, a variation on the standard OBPG NIR atmospheric correction with bio-optical iteration was considered more accurate due to the low SNR in MODIS SWIR bands (see Section 1.2) (Werdell et al., 2010). As in HT, this low-turbidity approach (LT) uses $2130 \mathrm{~nm}$ for cloud detection, masks stray light but not high light, and removes outliers based on the reflectance thresholds given above. Histogram analysis of retrievals for $R_{r s}(645)$ generally showed a population of slightly negative pixels in the darkest regions of the image, indicating a slight systematic bias due to sensor radiometric calibration or overcorrection for aerosols. The median of negative retrievals (not less than $-0.02 \mathrm{sr}^{-1}$ ) was therefore calculated for each scene (generally $\ll-0.001 \mathrm{sr}^{-1}$, but occasionally as high as $-0.002 \mathrm{sr}^{-1}$ ) and subtracted from all pixels processed in LT. This slight offset-used to compensate for minor calibration and atmospheric correction error in SeaDAS-has a negligible effect on turbid waters, but it improves coverage offshore because negative retrievals are subsequently eliminated.

Next the two 12gen schemes (LT \& HT) were merged. Histogram comparisons of low reflectance pixels in HT with those in LT revealed small biases in the SWIR approach (HT), possibly owing to the lack of vicarious calibration in MODIS SWIR bands. An offset was calculated to match the modes of HT and LT for low reflectance pixels (i.e. those not flagged as HILT) and added to the HT scenes. These offsets were found to be very small generally ( -0.002 to $0.002 \mathrm{sr}^{-1}$ ) and more frequently slightly negative, but helped insure a continuous geographic transition between algorithms. Finally, scenes were merged based on a threshold $R_{r s}(645)$ value of $0.01 \mathrm{sr}^{-1}$ (corresponding approximately to TSM of $9.5 \mathrm{mg} \mathrm{l}^{-1}$ (Miller \& McKee, 2004)) resulting in a "L2B" file (Fig. 3); i.e. LT values were applied to all pixels below this threshold, and HT values were retained elsewhere. It is noteworthy that threshold selection is applied to HT imagery-replacing low turbidity pixels with LT values-rather the other way around, which would be subject to large errors for regions with bio-optical iteration failure. Bio-optical iteration failure occurs when the estimation of NIR water leaving radiance for selecting the appropriate aerosol model fails to converge as described in (Bailey et al., 2010), and results in an 'atmospheric correction warning' flag and-in our experience in highly turbid waterssignificant underestimates of remote sensing reflectance in the red, as shown in Fig. 4.

Prior to merging HT and LT scenes, imagery was rejected in which $>85 \%$ of ocean pixels were masked for cloud. While this eliminated most heavily clouded scenes potentially susceptible to higher interpixel error in ocean color due to cloud and stray light effects, in many instances it failed to eliminate scenes with poor coverage of our sub-regions of interest and transects resulting from only partial granule coverage of the region (i.e. cloud cover was evaluated as a percentage of available non-land masked pixels in an image subset to our region, not of potential pixels covering the entire region). All scenes were therefore visually inspected and discarded for poor coverage deriving from transects and regions of interest lying off-granule (the overwhelming proportion of manually rejected scenes), and for heavy, patchy cumulous cloud cover, and-in a few instances-unrealistic mode offsets deriving from too few LT pixels available in the scene. Specifically, 115 of the remaining 700 scenes were discarded from the Aqua data set, and 148/757 from Terra.

\subsection{Finding optimal GSD}

The procedure for finding optimal GSD followed the theoretical approach outlined in Section 1. Tabulated data for SNR as a function of TOA radiances for each MODIS Aqua band and detector were provided for this study by the NASA MODIS Characterization Support Team (MCST) and were applied to Eq. (5). Their methodology for deriving on-orbit SNR is described in (Xiong, Sun, Barnes, \& Salomonson, 2010). At the time of writing, tabulation was not available for Terra, but based on preliminary results, it does not appear that differences will be high for band 1, and the Aqua values are applied here to Terra as well. Results showed small differences between the two instruments, with higher interpixel variability in Terra (e.g. Section 3.2), which may be a result of an overestimation of SNR.

For each QKM scene in each region, the transects shown in Fig. 2 were traversed using software developed in Matlab (www.mathworks.com). At each station, aggregations of $2 \times 2,3 \times 3,4 \times 4$, etc., pixels were evaluated until the coefficient of variability in $R_{r s}(645), \sigma_{\mathrm{i}}$, was greater than the noise, $\sigma_{\mathrm{t}}$. For each image, the actual resolution was calculated, and any scenes with pixels larger than $500 \mathrm{~m}$ were rejected, as was any station with $\sigma_{i}>1.5$ or where $>50 \%$ of pixels were undefined due to masking for clouds, land, etc. $\sigma_{\mathrm{i}}>1.5$ is defined as the standard deviation of the array equal to $150 \%$ of its average value, which is only likely if some of the pixels are unflagged land, cloud, or straylight. Once the interpixel variability threshold was met, the optimal GSD was defined as the average between the size of the inconclusive array $\left(\sigma_{i} \leq \sigma_{t}\right)$ and the size of the array which marked the upper limit of a GSD which could resolve significant differences in $R_{r s}(645)\left(\sigma_{\mathrm{i}}>\sigma_{\mathrm{t}}\right)$.

\subsection{Semivariance}

Semivariance analysis was conducted only within the plume regions shown in Fig. 2 and in the Sargasso Sea. Analysis relied upon Matlab code adapted from W. Schwanghart and available at Mathworks ${ }^{\circledR}$ (http:// www.mathworks.com/matlabcentral/fileexchange/20355), which tested 5000 random pairs of pixels in any orientation over a range of lags from 1 pixel distance to the maximum distance available in the subregion. Experimental variograms were then fitted using least square difference minimization to the spherical model:

$\gamma(h)=c_{0}+c_{1}\left(1.5\left(\frac{h}{a}\right)-0.5\left(\frac{h}{a}\right)^{3}\right)$

where $c_{0}, c_{1}, h$, and a are the nugget, sill, distance, and range, respectively (see Section 1.2). Every experimental semivariogram was visually inspected, and the range and sill of the smallest patch was manually selected based on the flattening of the experimental semivariance at shortest $h$ prior to fitting. Quality of fits of experimental data to the spherical model were evaluated qualitatively and rejected in cases where the modeled nugget was significantly different from the experimental, and where the shape could not be reproduced with a spherical model. Spherical fits to the experimental data are used here only to aid in visualization of results, and key parameters such as nugget, sill, and range are all derived from experimental results.

\section{Results and discussion}

\subsection{Tropical Storm Lee}

Two major tropical systems impacted the Chesapeake Bay region in late summer 2011 providing a good opportunity within the scope of this study to demonstrate some of the benefits of the methodology for turbid waters developed here. The first was Irene, which passed over the southern Mid-Atlantic States on August 27-28 as a Category 1 hurricane, bringing as much as $30 \mathrm{~cm}$ of rain to some portions of Maryland (http://www.nhc.noaa.gov/data/tcr/AL092011_Irene.pdf) 

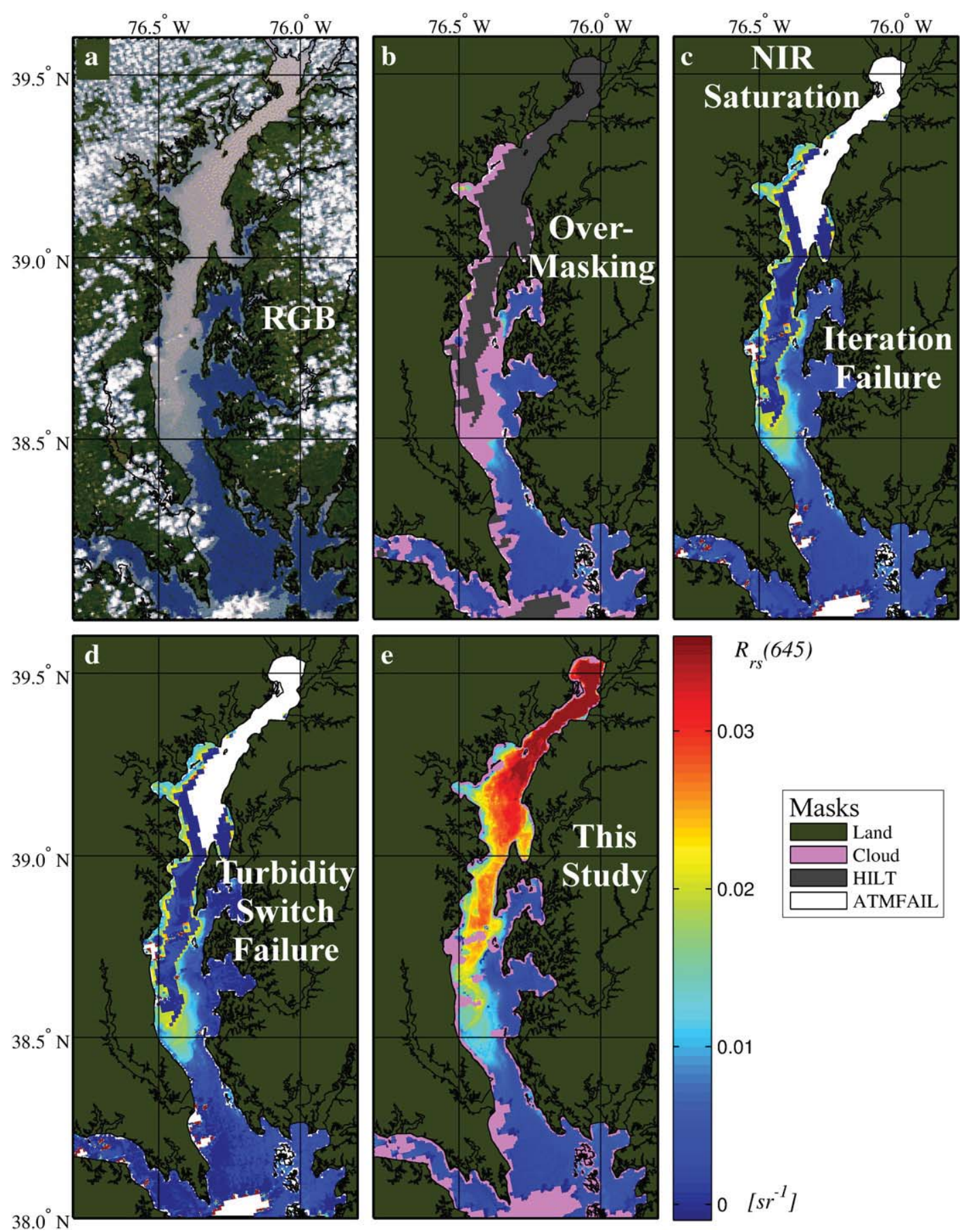

38.0

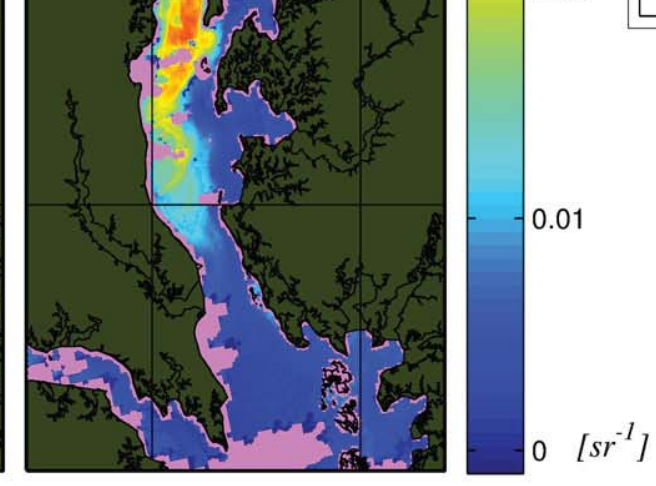

Fig. 4. An example image from the upper Chesapeake Bay on September 11, 2011 following Hurricane Irene and Tropical Storm Lee (MODIS granule A2011254180500) comparing various standard NIR and SWIR-NIR approaches to atmospheric correction in SeaDAS to the method used here. a) an enhanced true color image (HKM), b) standard bio-optical, iterative NIR process in SeaDAS (i.e. aer_opt $=-3$ ) with default masks (land, cloud/ice, and high light (HILT) at QKM, c) same as b with HILT and erroneous cloud masks removed to show underlying error in the bio-optical iteration within the plume, as well as atmospheric correction failure (ATMFAIL) owing most likely to NIR band saturation in extreme turbidity, d) standard SWIR-NIR product (i.e. aer_opt $=-9$ ) showing nearly identical results to $c$-though noisier in dark waters-due to failure to switch to SWIR bands for aerosol correction within the plume. The failure to switch probably arises from erroneously low $\mathrm{nL}_{\mathrm{w}}$ (see c).e) Results from this study processed as described in Section 2.1 .5 using SWIR bands in the plume, NIR bio-optical iteration in darker waters, and custom cloud, HILT, and stray light masking throughout with no reliance on NIR bands.

and saturating the surrounding watershed. While increased turbidity was detectable in MODIS imagery in the days following Irene due to the increased run-off and resuspension, the most dramatic impacts came over a week later when the remnants of Tropical Storm (T.S.) Lee deposited an addition $53 \mathrm{~cm}$ of rain over parts of the region based on National Oceanic and Atmospheric Administration (NOAA) gauge data (http://www.nhc.noaa.gov/data/tcr/AL132011_Lee.pdf). Flooding reached $6.7 \mathrm{~m}$ above flood stage on the Susquehanna
River, and on September 6, the Conowingo Dam at the head of Chesapeake Bay was opened to relieve the flooding, increasing flow from $\sim 2.3 \mathrm{~m}^{3} \mathrm{~s}^{-1}$ to $17.0 \mathrm{~m}^{3} \mathrm{~s}^{-1}$ (http://waterdata.usgs.gov/usa/nwis/ uv?01578310) and releasing over the next several days a turbidity plume extending nearly $150 \mathrm{~km}$ down the Bay (Figs. 4 and 5).

On September 12 and 13, field measurements of TSM were made within the plume (Fig. 5) following the methods described in (Ondrusek et al., 2012). Applying the algorithm of (Ondrusek et al., 


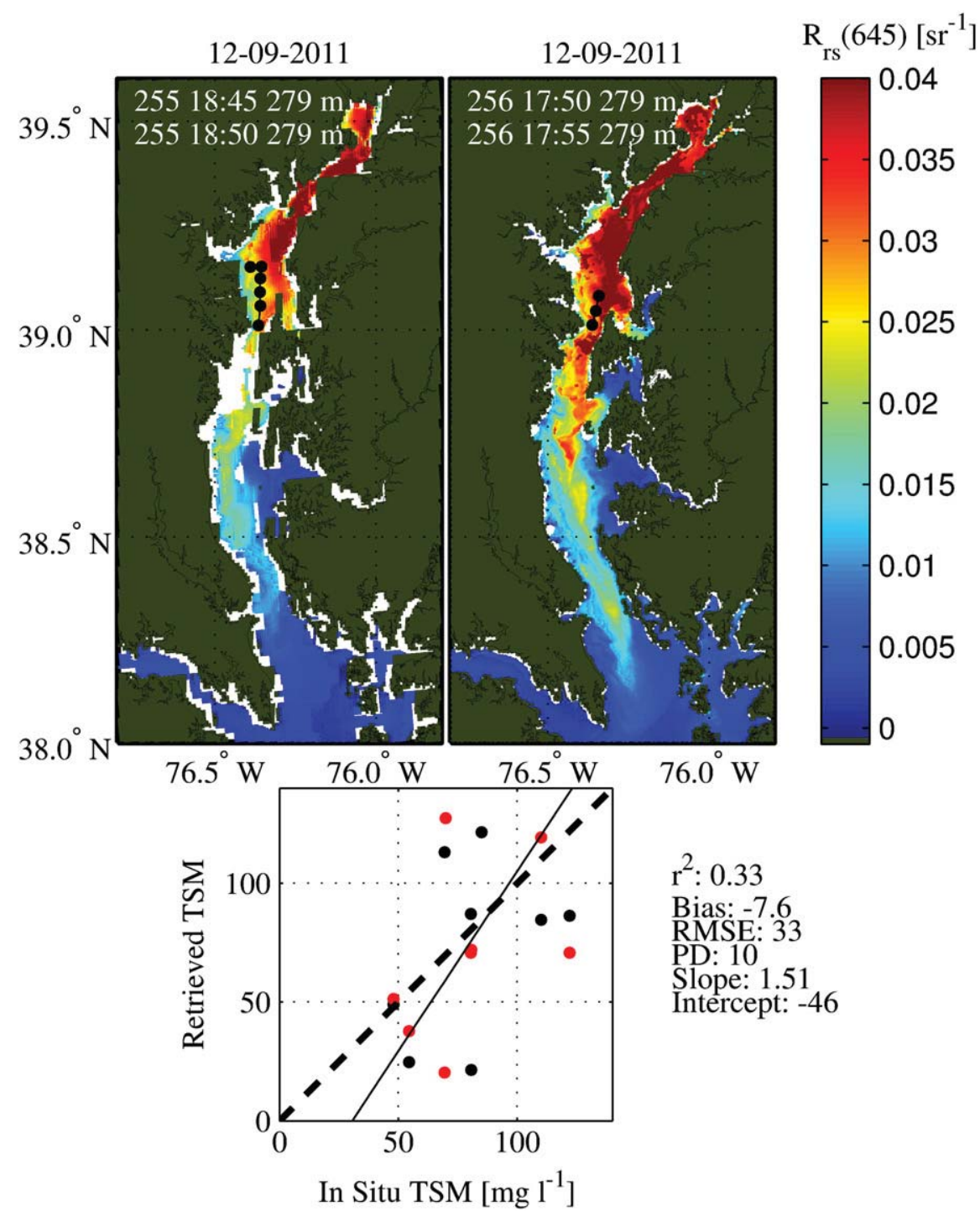

Fig. 5. Upper panels show field collection sites for September 12-13, 2011 overlaid on Aqua retrievals of $R_{r s}(645)$ derived as per Section 2.1.5. White pixels represent masking for clouds and stray light around clouds and land. Image days, times, and resolution are noted in the northwestern corners of each. Match-ups between TSM retrieved using (Ondrusek et al., 2012) and field measurements are shown in the bottom plot together with 1:1 line (dashed), fit line (solid), and regression statistics including $r^{2}$, bias, root mean square error (RMSE), percent difference (PD), slope and intercept of the fit. Retrievals from Aqua are in red, Terra are black.

2012), TSM was retrieved from MODIS imagery processed as described in Section 2.1.5 and matched to field stations based on a $3 \times 3$ pixel array within $3.5 \mathrm{~h}$. Given the cubic nature of the TSM algorithm, and the fact that it was tuned to considerably lower values of TSM than those shown here, the retrievals in the most reflective waters tended to be overestimated. For this reason retrievals of $>150 \mathrm{mg} \mathrm{l}^{-1}$ (two stations) were excluded. The lower panel in Fig. 5 shows reasonable agreement between retrievals and field measurements, although the sample size is quite limited, and correlations may be hampered by the lack of any data in the low turbidity portion of the graph $\left(<\sim 50 \mathrm{mg} \mathrm{L}^{-1}\right)$.

Figs. $6 a$ and $b$ show the results of GSD and semivariogram analysis, respectively. Within the plume, the size of the pixel arrays around virtual stations showing interpixel variability above the noise threshold (i.e. variability in ocean color) is never more than $5 \times 5$, and most often just $2 \times 2$ (nominally $250 \mathrm{~m}$ pixels). An increase in necessary array size (decrease in resolution) can be seen in the estuary (here the central and lower Chesapeake Bay), particularly in image A2011255. On the shelf, resolutions as low as $4 \mathrm{~km}$ were sometimes adequate ( $16 \times 16$ pixels), although this varied highly from image to image. Within the plume itself, the smallest patches had ranges of $\sim 12-20 \mathrm{~km}$ (Fig. $6 \mathrm{~b}$ ), and the semivariogram nuggets were $<\sim 0.15$, indicating that $>85 \%$ of the interpixel variability within the patch was detectable at QKM.

\subsection{Optimal ground space distance}

Optimal GSD results from virtual transects in each region are presented in Fig. 7 and Table 1. In general, the pixel size required to capture variability in ocean color increases from inshore to offshore as expected. GSD requirements have large spatial and seasonal variability among the over 19,000 virtual stations remaining after quality in the imagery was assured-and often are limited by the $375 \mathrm{~m}$ lower bound of our analysis-but average between $522 \pm 57 \mathrm{~m}$ in combined plume regions and $1354 \pm 92 \mathrm{~m}$ in the open ocean.

For nearly all regions, the results for the sub-regions we selected (i.e. plume, nearshore, and shelf waters) were statistically different (ANOVA, p $\ll 0.01$, see Table 1 ). An exception was found between nearshore and shelf waters in the Amazon region. Within sub-regions, some significant differences (eight of 12) were found between Aqua 
a

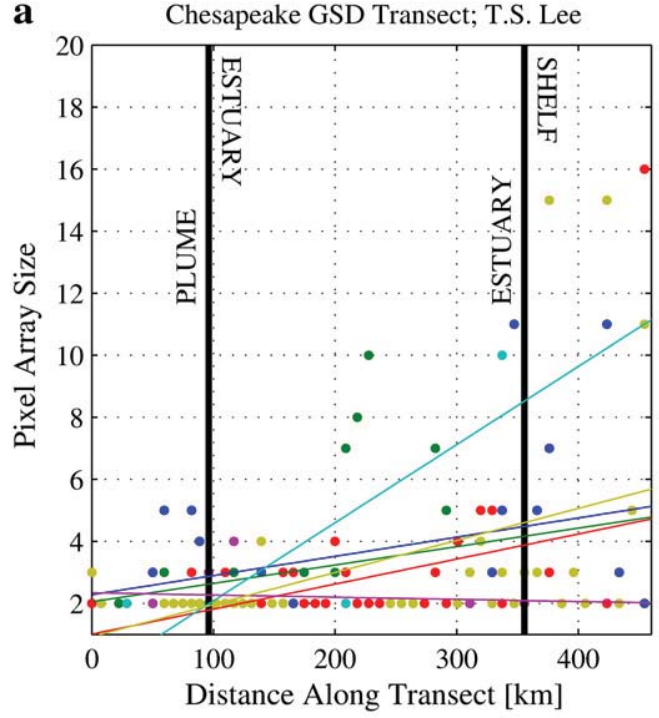

b

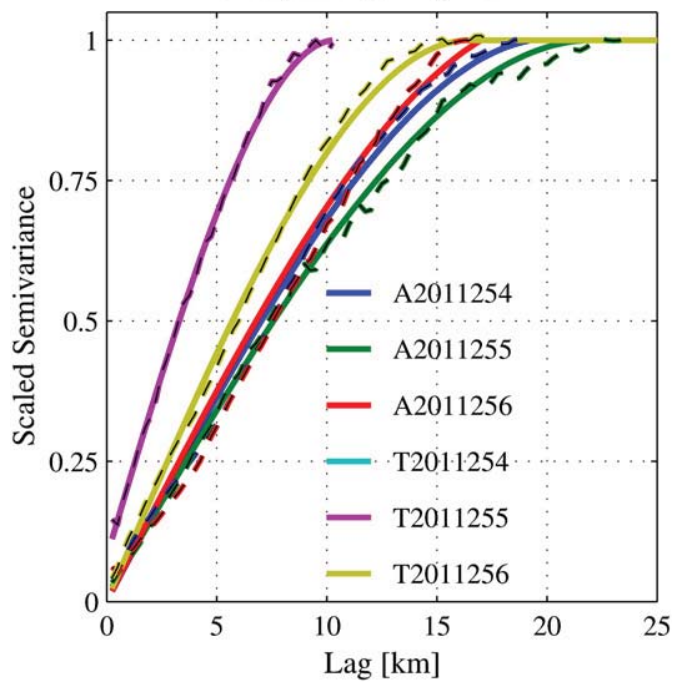

Fig. 6. Examples of both optimal GSD results (a) and semivariograms (b) from the Chesapeake Bay region following the passage of Hurricane Irene and Tropical Storm Lee. Colors in both a and b represent individual MODIS QKM images (legend in b). Colored lines in a are linear fits to the data from all virtual stations (colored dots) along the transect showing general trends toward increasing GSD with distance from the plume. Each dot in a represents the pixel array size at which the interpixel variability in ocean color exceeds that of instrumental or atmospheric noise. Coarser resolution would overlook these differences in ocean color. In b, experimental semivariograms (dashed) are overlaid on spherical fits (solid). Nuggets all fall below $\sim 0.15$ indicating that QKM imagery is capturing $>85 \%$ of the overall variability within the patch size (i.e. range, $\sim 12-20 \mathrm{~km}$ ).

and Terra satellite results, with Terra falling $15 \%$ lower on average than Aqua. The discrepancy likely derives from higher noise levels in the Terra instrument which are not accounted for in the on-orbit noise estimation data available (see Section 2.2).

Only four of the 12 comparisons between GSD during peak and nadir river flow periods showed significant differences: in the plume sub-regions of the Chesapeake and Mississippi, and the nearshore and shelf sub-regions of the Yangtze.

A dip in the optimal GSD and reduction in inter-image variability is visible in the plume region of the Amazon between about 200 and $350 \mathrm{~km}$ (Fig. 7) indicating a stronger and less transient gradient in ocean color. This suggests that the geographic and temporal extent of this plume is comparatively stable relative to the other regions studied.

It is not immediately apparent what drives the spatial variability we see in the Sargasso Sea, where optimal GSD varies between station averages of $\sim 750-4400 \mathrm{~m}$. The region was considerably larger than the others ( $10^{\circ}$ latitude by $10^{\circ}$ longitude) and prone to heavy cloud cover. Of the over 1100 granules with at least some coverage of the region during the periods chosen, only 109 were retained for analysis after elimination for 1) having no open sky pixels over the virtual transect-which stretched the extent of the region from the southwest to the northeastor 2 ) for excessive cloud cover ( $>65 \%$ of pixels). Remaining images were never completely cloud free ( $12 \%$ minimum), and averaged $46 \%$ clouded overall. If stray light masking around clouds was insufficient and/or cloud shadows a factor, this may have been mistaken by the GSD analysis for interpixel variability in ocean color, thereby reducing the GSD results in cloudy scenes.

\subsection{Semivariogram analysis}

Semivariograms-measures of the variability and spatial extent of ocean color patches-differed significantly in the four river plume regions generally as a function of the relative size of the rivers themselves (Table 2, Figs. 8-10). The largest plumes at the Amazon and Yangtze Rivers had the largest coherent patches $(87 \pm 21 \mathrm{~km}, 62 \pm 4 \mathrm{~km}$, respectively), followed by the Mississippi ( $43 \pm 4 \mathrm{~km}$ ) and the Chesapeake $(19 \pm 6 \mathrm{~km})$. Due to the large patch sizes, semivariograms were largely insensitive to the resolution used to measure them. These patches do not represent homogeneous waters, but spatial scales beyond which variability in ocean color does not increase-at least for some distance. Variability within patches also depended on river size with sill values declining from $1.25 \pm 0.34 \mathrm{sr}^{-1}$ in the Amazon plume, to $0.61 \pm 0.30 \mathrm{sr}^{-1}$ at the Yangtze, and $0.32 \pm 0.26 \mathrm{sr}^{-1}$ and $0.12 \pm 0.09 \mathrm{sr}^{-1}$ at the Mississippi and Chesapeake, respectively. By contrast, the proportion of variability resolvable at a given resolution (i.e. 1 -nugget), varied from $91 \%$ at the Chesapeake to $95 \%, 96 \%$, and 98\% at the Yangtze, Mississippi, and Amazon, respectively. The nugget was the only parameter that showed significant differences between seasons, with more variability going undetected during nadir flow seasons, particularly in the Chesapeake (Table 2). In the Chesapeake, large nuggets during nadir flow of the Susquehanna River may result from the influence of the many other un-gauged tributaries feeding into the Susquehanna plume. The spherical model (Eq. (6); used only for data visualization) fit the empirical data about $70 \%$ of the time based on the criteria outlined in Section 2.3, and was more likely to fit well if the range was short.

Results from our control region in the Sargasso Sea were considerably different from those in the plume regions. Patch size was much larger and more variable at $180 \pm 77 \mathrm{~km}$, while the variability within the patches was $2-3$ orders of magnitude lower $\left(4.1 \times 10^{-7} \pm\right.$ $5.0 \times 10^{-7} \mathrm{sr}^{-1}$ ) than in the plumes, and degree of unresolved variability increased to $34 \%$ on average. Unlike other regions, the sill was highly sensitive to resolution (Table 2), although the reasons for this are not immediately apparent, and it was not reflected in other semivariance parameters.

Figs. 8-10 show experimental and fitted semivariograms in greater detail for each region at HKM (chosen for being closest to GSD results (Table 1), and not significantly different from other resolutions (Table 2)) together with distributions of the parameters summarized in Table 2. Due to the similarities in semivariograms discussed above, these figures are separated into the largest rivers (Fig. 8), moderately large rivers (Fig. 9), and offshore (Fig. 10). Overall, the smaller patches (lower range) tended to fit better to the spherical model (Eq. (6); dashed green and brown lines). Experimental semivariograms (gray lines) were considerably noisier in the Sargasso Sea owing to the variability in the reflectance signal being extremely low, but still matched the spherical model in the majority of cases. The low sill values found offshore were also likely the reason for the notably higher degree of unresolved variability as a proportion of the sill. Had the nuggets not 

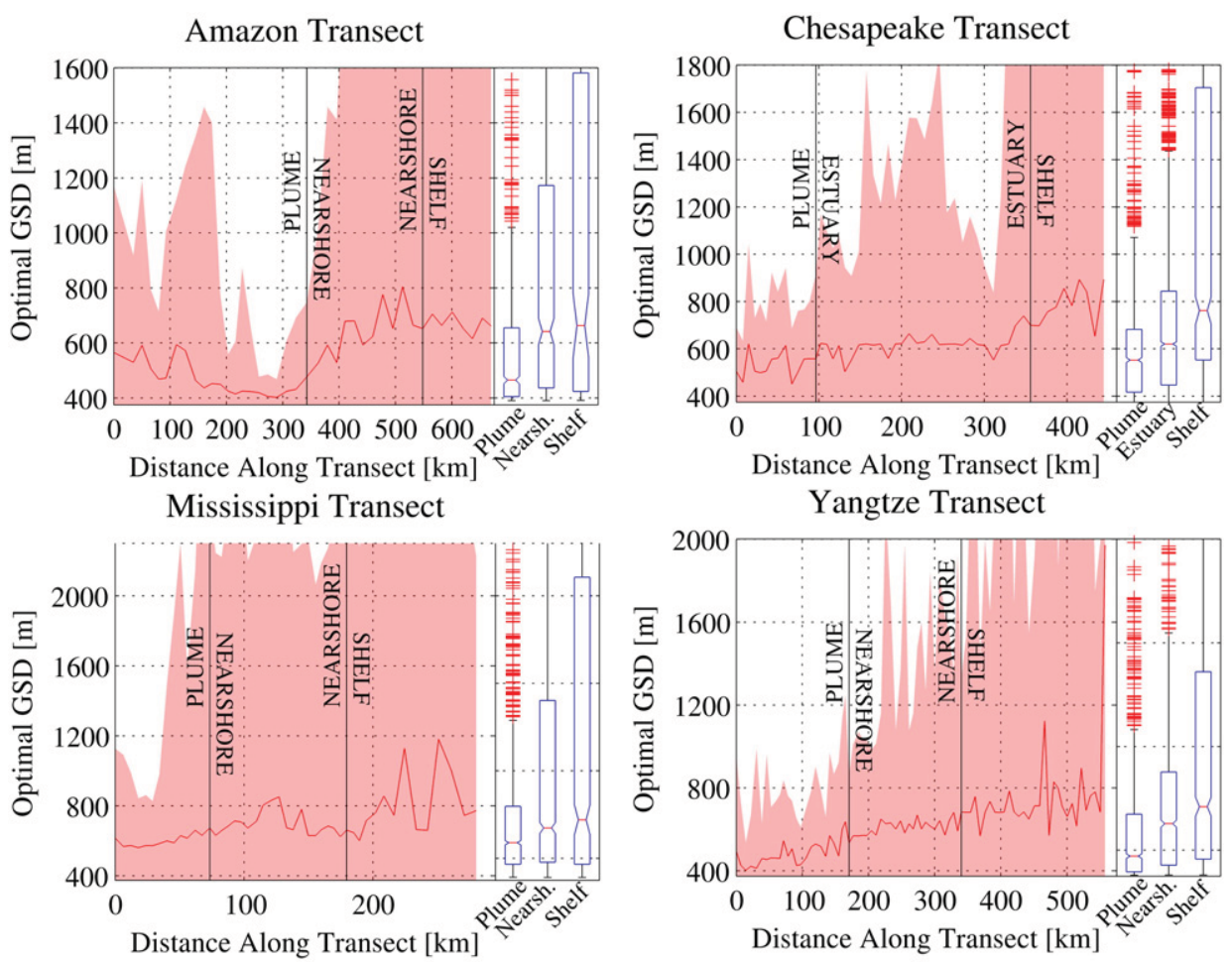

Sargasso Transect

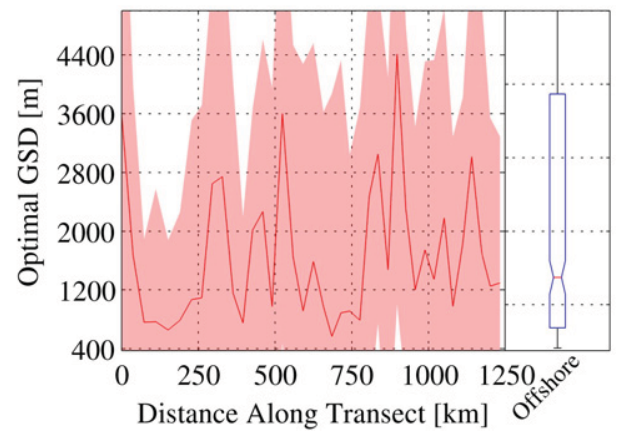

Fig. 7. Optimal ground space distance for each region as a function of distance along the river plume transects in Fig. 3 and the Sargasso Sea (note changes in scales of GSD and distance). Sub-regions are summarized in the box-whisker diagrams to the right of each transect. As with all box-whisker diagrams in this manuscript, the thin central line shows the population median, boxes extend to the first and third quartiles, vertical lines extend from boxes to $99 \%$ of the data, and extreme outliers are shown as red plus symbols (partially truncated to preserve scale on occasion). The thick, solid red lines along the transects represent the median values of all satellite images for the region over all seasons (see text for numbers of images), and the shaded regions are one standard deviation.

been normalized to sill values in the offshore region, their magnitudes would have also been orders of magnitude lower than those found in the river plumes.

It is perhaps somewhat surprising that neither satellite resolution nor season generally play a significant role in the spatial scales of patchiness in the plume regions. In part, this is attributable to the higher degree of variability among all images as shown in the box-whisker plots in Figs. 8-10. Another factor-at least as far as resolution comparisons are concerned-may be the size of the patches themselves. Patches were identified visually as the smallest ranges within which the semivariance plateaued with a discernible sill, and yet they were always much larger than many dozens of pixels; the smallest average for region, season, and resolution being $12 \mathrm{~km}$ at QKM, or $\sim 48$ pixels. This likely explains why results did not vary notably between $1 \mathrm{KM}$, HKM, and QKM.

\section{Summary}

Improving spatial resolution in future ocean color satellite sensors such as GEO-CAPE incurs additional expense and complexity of instrument design, and should be justified by increased capabilities. Most of the data available from low Earth orbiters has historically been collected at $\sim 1 \mathrm{~km}$ resolution, although exceptions are available from MERIS ( $300 \mathrm{~m}$ ), some bands of MODIS ( $250 \mathrm{~m}$ and $500 \mathrm{~m}$ ), and others. Previous studies have looked at high resolution space- and air-borne imagery (generally a small number of scenes) to understand what resolution is adequate for mapping biogeochemical property distributions in coastal and inland waters. Here, we have expanded upon and developed analytical methodologies for satellite ocean color processing and for determining optimal GSD, applying them to four years of MODIS imagery (over 3000 images) from the red $645 \mathrm{~nm}$ band at QKM, HKM, and $1 \mathrm{KM}$ resolution.

For the purpose of demonstrating the method used for satellite imagery processing as well as the spatial statistics tools employed here, the period following two tropical systems crossing the Chesapeake Bay was examined in detail. Next, four river plumes at the Amazon, Chesapeake, Mississippi, and Yangtze Rivers were studied with adjacent waters, and an offshore region was shown for comparison. Regions were sectioned into sub-regional environments, transected by virtual stations used to extract satellite imagery, and analyzed for 
Table 1

Median optimal GSD for each region as a function of season, satellite, and sub-region. One-way ANOVA tests between adjacent values indicate the likelihood that populations have a significantly different (red cells) or similar (green cells) median. Comparisons with p-values $>0.05$, between $0.01-0.05,0.001-0.01$, and $<0.001$ are labeled NS, $>$, <, and $\ll$, respectively. All comparisons between Plume and Shelf waters were significantly different ( $\mathrm{p} \ll 0.01)$. The summary at the bottom of the table includes the mean GSD and numbers of virtual stations $(\mathrm{N})$ used in each subregion.

\begin{tabular}{|c|c|c|c|c|c|c|c|}
\hline & & Plume & $\leftrightarrow$ & Nearshore & $\leftrightarrow$ & Shelf & Offshore \\
\hline \multirow[t]{6}{*}{ Amazon } & \multirow{3}{*}{$\begin{array}{c}\text { Peak } \\
\uparrow \\
\text { Nadir }\end{array}$} & 469 & << & 593 & $>$ & 656 & \\
\hline & & NS & & NS & & NS & \\
\hline & & 438 & $<<$ & 647 & $>$ & 665 & \\
\hline & \multirow{3}{*}{$\begin{array}{c}\text { Aqua } \\
\uparrow \\
\text { Terra }\end{array}$} & 506 & $<<$ & 659 & $<$ & 919 & \\
\hline & & $<<$ & & $>$ & & $<<$ & \\
\hline & & 464 & $<<$ & 612 & NS & 593 & \\
\hline \multirow[t]{6}{*}{ Chesapeake } & \multirow{3}{*}{$\begin{array}{c}\text { Peak } \\
\uparrow \\
\text { Nadir }\end{array}$} & 558 & $<<$ & 621 & $<<$ & 761 & \\
\hline & & $<<$ & & NS & & NS & \\
\hline & & 493 & $<<$ & 620 & $<<$ & 799 & \\
\hline & \multirow{3}{*}{$\begin{array}{c}\text { Aqua } \\
\uparrow \\
\downarrow \\
\text { Terra }\end{array}$} & 558 & $<<$ & 640 & $<<$ & 840 & \\
\hline & & $<<$ & & NS & & NS & \\
\hline & & 505 & $<<$ & 561 & $<<$ & 758 & \\
\hline \multirow[t]{6}{*}{ Mississippi } & \multirow{3}{*}{$\begin{array}{c}\text { Peak } \\
\uparrow \\
\text { Nadir } \\
\end{array}$} & 587 & $<<$ & 675 & $<<$ & 712 & \\
\hline & & $<<$ & & NS & & NS & \\
\hline & & 602 & $<<$ & 672 & $<<$ & 779 & \\
\hline & \multirow{3}{*}{$\begin{array}{c}\text { Aqua } \\
\uparrow \\
\text { Terra }\end{array}$} & 629 & $<<$ & 706 & $<<$ & 983 & \\
\hline & & NS & & $<<$ & & $<<$ & \\
\hline & & 574 & $<<$ & 663 & $<<$ & 664 & \\
\hline \multirow[t]{6}{*}{ Yangtze } & \multirow{3}{*}{$\begin{array}{c}\text { Peak } \\
\uparrow \\
\text { Nadir } \\
\end{array}$} & 472 & $>$ & 535 & $<<$ & 656 & \\
\hline & & NS & & $<<$ & & $<<$ & \\
\hline & & 471 & $<<$ & 635 & $<<$ & 713 & \\
\hline & \multirow{3}{*}{$\begin{array}{c}\text { Aqua } \\
\uparrow \\
\downarrow \\
\text { Terra } \\
\end{array}$} & 568 & $<<$ & 642 & $<<$ & 890 & \\
\hline & & $<<$ & & $<<$ & & $<<$ & \\
\hline & & 462 & $<<$ & 595 & $<<$ & 662 & \\
\hline \multirow[t]{3}{*}{ Sargasso } & \multirow{3}{*}{$\begin{array}{c}\text { Aqua } \\
\uparrow \\
\text { Terra } \\
\end{array}$} & & & & & & 1262 \\
\hline & & & & & & & NS \\
\hline & & & & & & & 1446 \\
\hline Summary & & \multicolumn{2}{|c|}{$522 \pm 57$} & \multicolumn{2}{|c|}{$630 \pm 43$} & $753 \pm 106$ & $1354 \pm 92$ \\
\hline $\mathrm{N}$ & & \multicolumn{2}{|c|}{6226} & \multicolumn{2}{|l|}{9299} & 3232 & 471 \\
\hline
\end{tabular}

optimal ground space distance, spatial scales of variability, and the proportion of variability detectable within plume patches.

Unsurprisingly, the plumes themselves were found to be the most spatially heterogeneous with scales of patchiness (i.e. ranges) on the order of $\sim 20-90 \mathrm{~km}$ compared with $\sim 180 \mathrm{~km}$ offshore. In plumes, these scales correspond to processes such as fronts, eddies and filaments, synoptic storm outflows and resuspension, and internal tides, while in coastal waters they may also correspond with phytoplankton blooms, inertial, internal and solitary waves. Patch sizes found offshore correspond to the scale of larger phenomena such as surface tides and seasonal changes in mixed layer depth and biomass cycles (Dickey et al., 2006). Patches were large enough that the resolution (QKM, HKM, or $1 \mathrm{KM}$ ) used to calculate the semivariance function was not a significant factor. The ranges in the river plumes were roughly proportional to the sizes of the rivers studied, as were the degrees of variability (i.e. sills) within the patches. The proportions of the variability resolved (i.e. nuggets) in the patches were generally high at all resolutions measured, and varied between plume regions from $85 \%$ to $99 \%$, with the lower values found in the Chesapeake Bay.

Significant differences exist between the spatial resolution required to detect interpixel ocean color variability between the three coastal environments ( $\sim 520 \mathrm{~m}, 630 \mathrm{~m}, 750 \mathrm{~m}$, and at the plumes, nearshore, and shelf, respectively) when both the peak plume and nadir plumes seasons are taken together. Separately, the nadir river flow seasons tend to require slightly lower GSD ( $7 \%-12 \%$ in the plume, mean across subregions $4 \%$ ) than peak flow seasons. Results from Terra were generally somewhat lower than those from Aqua ( $12 \%$ lower GSD in the plumes) possibly as a result of higher, unaccounted for noise in the instrument.
Table 2

Experimental semivariance component data for each region, season, and resolution. Few significant differences were found in the between Aqua and Terra or between $1 \mathrm{KM}$, HKM, and QKM within a region ( $\mathrm{p}>0.01$ ). Peak nugget populations tended to be slightly lower than nadir $(1 \%, \mathrm{p} \ll 0.01)$, except in the Chesapeake where the difference was pronounced (10\%). $\mathrm{N}$ is the number of semivariograms used in each region/season/resolution and $\mathrm{n}$ is the number successfully fit to the spherical model.

\begin{tabular}{|c|c|c|c|c|c|c|}
\hline & & Season & $\begin{array}{c}\text { Nugget } \\
{[\%]}\end{array}$ & $\begin{array}{c}\text { Range } \\
{[\mathrm{km}]}\end{array}$ & $\begin{array}{c}\text { Sill } \\
{\left[\times 10^{-4} 1 / \mathrm{sr}\right]}\end{array}$ & $\mathrm{N}(\mathrm{n})$ \\
\hline \multirow[t]{6}{*}{ Amazon } & \multirow[t]{2}{*}{$1 \mathrm{KM}$} & Peak & 2 & 110 & 1.630 & $34(16)$ \\
\hline & & Nadir & 1 & 50 & 0.692 & $51(33)$ \\
\hline & \multirow[t]{2}{*}{ HKM } & Peak & 2 & 93 & 1.275 & $36(22)$ \\
\hline & & Nadir & 1 & 79 & 1.086 & $69(47)$ \\
\hline & \multirow[t]{2}{*}{ QKM } & Peak & 2 & 90 & 1.271 & $54(41)$ \\
\hline & & Nadir & 3 & 98 & 1.537 & $90(58)$ \\
\hline \multirow[t]{6}{*}{ Chesapeake } & \multirow[t]{2}{*}{$1 \mathrm{KM}$} & Peak & 3 & 26 & 0.187 & $55(26)$ \\
\hline & & Nadir & 15 & 16 & 0.039 & $47(41)$ \\
\hline & \multirow[t]{2}{*}{ HKM } & Peak & 4 & 23 & 0.216 & $73(45)$ \\
\hline & & Nadir & 14 & 13 & 0.041 & $35(34)$ \\
\hline & \multirow[t]{2}{*}{ QKM } & Peak & 5 & 23 & 0.216 & $75(29)$ \\
\hline & & Nadir & 13 & 12 & 0.045 & $37(14)$ \\
\hline \multirow[t]{6}{*}{ Mississippi } & \multirow[t]{2}{*}{$1 \mathrm{KM}$} & Peak & 2 & 44 & 0.518 & 136(91) \\
\hline & & Nadir & 4 & 51 & 0.067 & $123(82)$ \\
\hline & \multirow[t]{2}{*}{ HKM } & Peak & 3 & 41 & 0.572 & $140(115)$ \\
\hline & & Nadir & 4 & 43 & 0.095 & 110(87) \\
\hline & \multirow[t]{2}{*}{ QKM } & Peak & 3 & 41 & 0.580 & $143(124)$ \\
\hline & & Nadir & 6 & 40 & 0.103 & 126(109) \\
\hline \multirow[t]{6}{*}{ Yangtze } & \multirow[t]{2}{*}{$1 \mathrm{KM}$} & Peak & 4 & 68 & 0.334 & $36(28)$ \\
\hline & & Nadir & 6 & 59 & 0.888 & $82(60)$ \\
\hline & \multirow[t]{2}{*}{ HKM } & Peak & 4 & 65 & 0.329 & $39(32)$ \\
\hline & & Nadir & 4 & 59 & 0.906 & $81(63)$ \\
\hline & \multirow[t]{2}{*}{ QKM } & Peak & 4 & 65 & 0.329 & $39(19)$ \\
\hline & & Nadir & 5 & 58 & 0.848 & $83(47)$ \\
\hline \multirow[t]{6}{*}{ Sargasso } & \multirow[t]{2}{*}{$1 \mathrm{KM}$} & May & 25 & 284 & 0.00008 & $45(27)$ \\
\hline & & November & 38 & 274 & 0.00011 & $24(17)$ \\
\hline & \multirow[t]{2}{*}{ HKM } & May & 44 & 151 & 0.00160 & $45(43)$ \\
\hline & & November & 32 & 136 & 0.00270 & $20(18)$ \\
\hline & \multirow[t]{2}{*}{ QKM } & May & 36 & 115 & 0.00700 & $52(52)$ \\
\hline & & November & 30 & 122 & 0.01295 & $32(32)$ \\
\hline
\end{tabular}

The offshore region exhibited variability several orders of magnitude lower than in the plumes, and that variability was not as well resolved (56\%-75\%). However, a considerably larger pixel size $(\sim 1400 \mathrm{~m})$ was found to be adequate for resolving interpixel variability.

The approach suggested here for processing MODIS imagery with SeaDAS in highly turbid regions overcomes the problems diagramed in Fig. 4 such as over-masking, erroneous cloud detection, iteration failure of the aerosol algorithm, and bad switching between SWIR and NIR aerosol models, and suggests a future avenue for quantifying pixelspecific $\Delta R_{r s}$ at ocean color bands other than $645 \mathrm{~nm}$ in MODIS (i.e. Eqs. (1)-(5)). This approach mitigates problems found using the operational SeaDAS SWIR-NIR approach in the Chesapeake Bay (Werdell et al., 2010) (i.e. higher frequency of negative retrievals and increased noise in retrievals) by using a dark water mode offset on SWIR retrievals to accommodate the lack of vicarious calibration, by unmasking high turbidity waters previously hidden by erroneous cloud flags and NIR band saturation, and by only applying SWIR-selected aerosols in these turbid waters where SNR in band 1 MODIS is less of an issue. During the flooding following T.S. Lee in the Chesapeake, several clear days provided good satellite observing, and field data were collected by associates in the resulting plume. Satellite retrievals of TSM showed reasonable agreement with those collected in the field, though the dynamic range did not include low turbidity measurements, the sample size was small, 

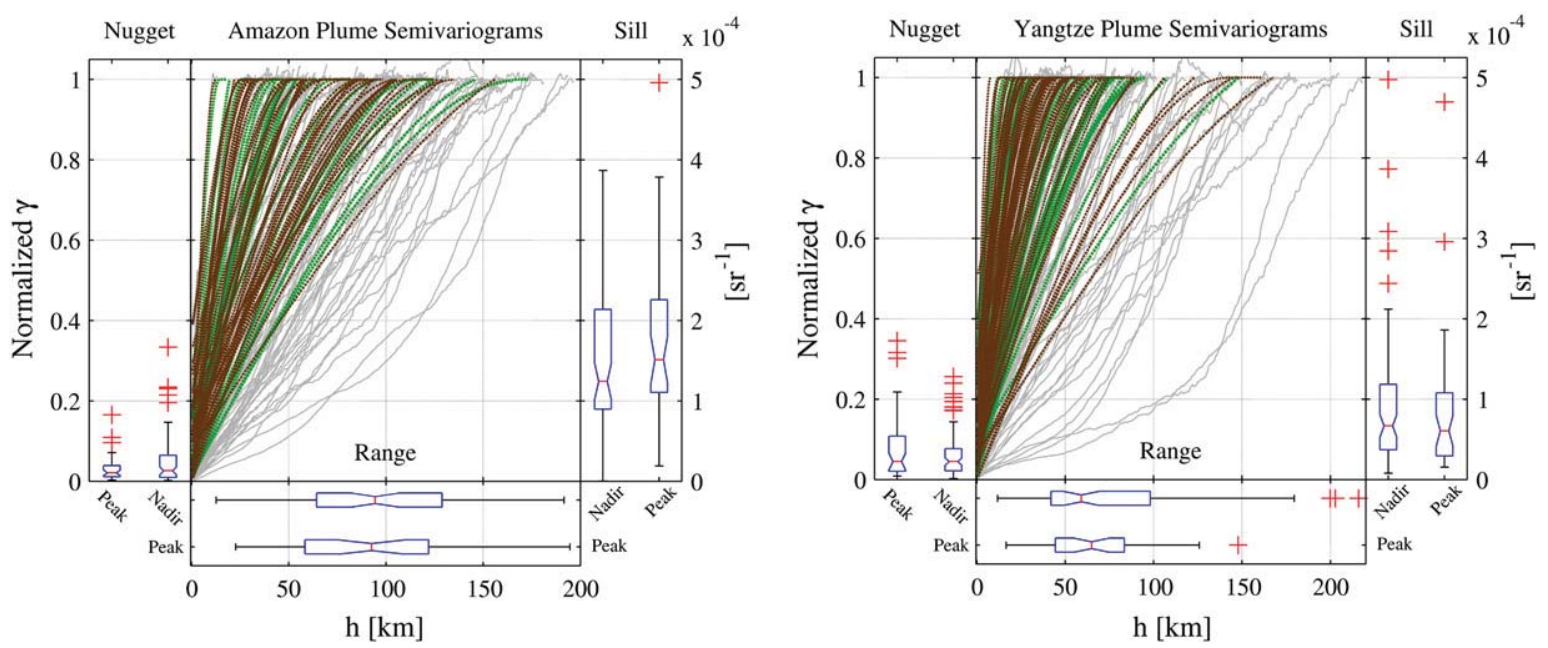

Fig. 8. Semivariograms and related parameters from HKM MODIS imagery at the two larger river plume regions, the Amazon and the Yangtze. The fitted semivariogram curves (dashed lines in central area of each plot) are normalized to sill values; non-normalized sill distributions of the experimental data are shown in right-hand box-whisker diagram (see Fig. 6 caption for details regarding box-whisker diagrams). Fitted peak (brown dashed lines) and nadir (green dashed lines) river flow periods are overlaid on experimental data (grey lines) where they matched well, which happened more often when the range was short $(<\sim 100 \mathrm{~km})$. Nugget distributions of non-fitted, experimental data (also normalized) are shown in the left-hand box-whisker plots by season, and ranges in the bottom box-whisker plots. Differences between seasons and MODIS instruments were small (see text).

and correlations were not strong $\left(r^{2}=0.33\right)$. Remote sensing reflectance retrievals show realistic geographic patterns throughout the plumes and darker waters with no obvious discontinuities, little evidence of unmasked stray light or clouds, and no sign of iterative failure of atmospheric correction (e.g. Figs. 2,4,5).

The primary purpose of this study was the investigation of spatial statistics leading to a better understanding of instrument requirements for future satellite missions. Analytically, the results were more dependent upon interpixel variability in ocean color rather than absolute magnitudes, and no radiometric validation of retrievals was attempted. However, validation could precede as more field measurements of ocean color and biogeochemical properties become available in these extreme environments. Validation could then be extended to retrievals of biogeochemical properties such as TSM, provided field data were collected to regionally characterize absorption effects (e.g. from CDOM or phytoplankton pigments) on reflectance at $645 \mathrm{~nm}$. With better characterization of on-orbit instrument SNR and a method for aerosol removal, it may be possible in the future to further refine the GSD approach using data from the Hyperspectral Imager for the Coastal Ocean (HICO) instrument aboard the International Space Station, which collects episodic data of the regions studied here at a spatial resolution of about $100 \mathrm{~m}$. The result would be to lower the optimal GSD lower limit to $150 \mathrm{~m}$, which, while not relevant in most of the nearshore, shelf, or offshore waters studied here, may be important to inland waters and turbid river outflows. Similarly, given sensor-specific SNR as a function of $L_{t}$, this analysis could be expanded to other visible wavebands using archived MERIS $300 \mathrm{~m}$ data, although the lower limit would increase somewhat from $375 \mathrm{~m}$ to $450 \mathrm{~m}$. In addition to better understanding spatial variability in ocean color, the methods described here may be extrapolated to develop pixel-specific maps of ocean color uncertainty for remote sensing reflectance products derived from each of these instruments, provided the requisite sensitivity characterizations were available.

\section{Acknowledgments}

The authors wish to especially thank Michael Ondrusek at NOAA/ NESDIS/STAR/SOCD for providing field measurements of TSM following T.S. Lee. Thanks also to Xiaoxiong Xiong and Amit Angal of the NASA MODIS Characterization Support Team (MCST), and to Gerhardt Meister of the NASA Ocean Biology Processing Group (OBPG) for
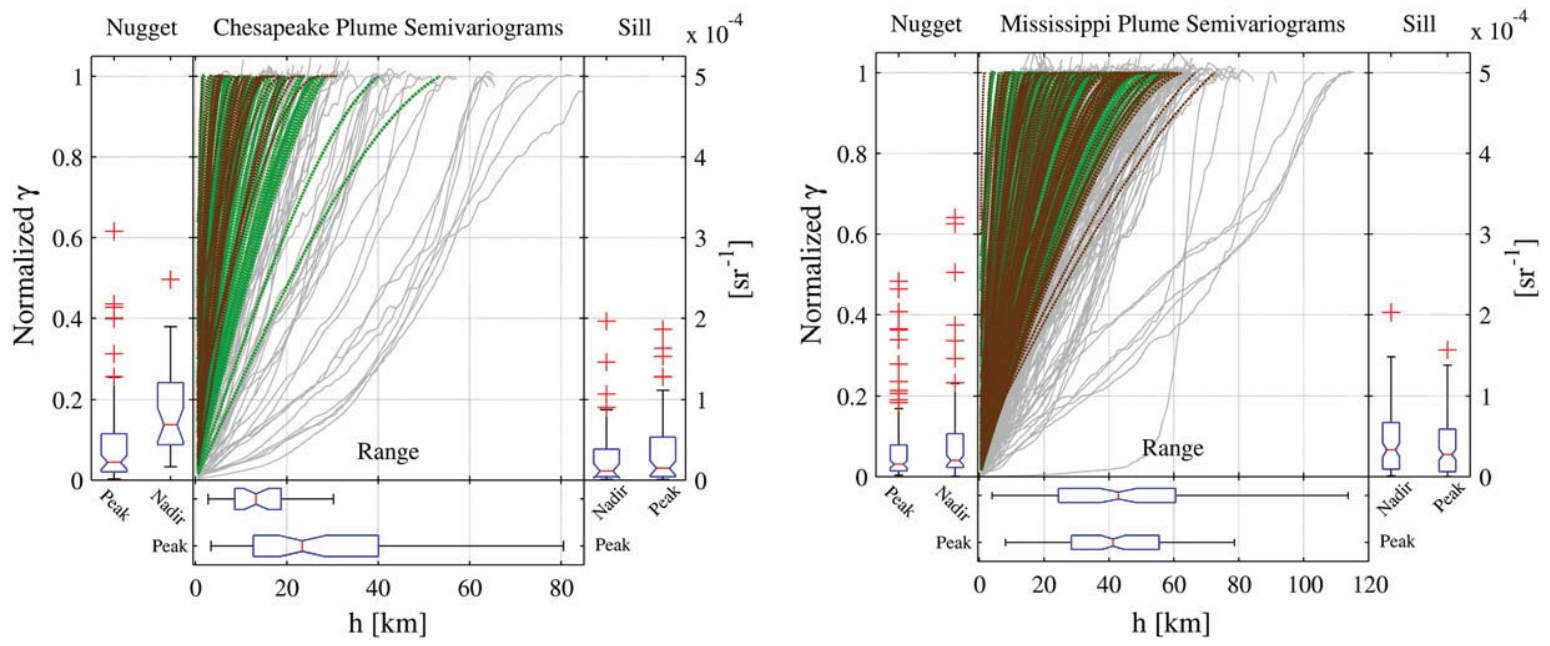

Fig. 9. Semivariograms and related parameters from HKM MODIS imagery at the two smaller river plume regions, the Chesapeake Bay/Susquehanna and Mississippi (see Figs. 7 \& 8 for descriptive details). 


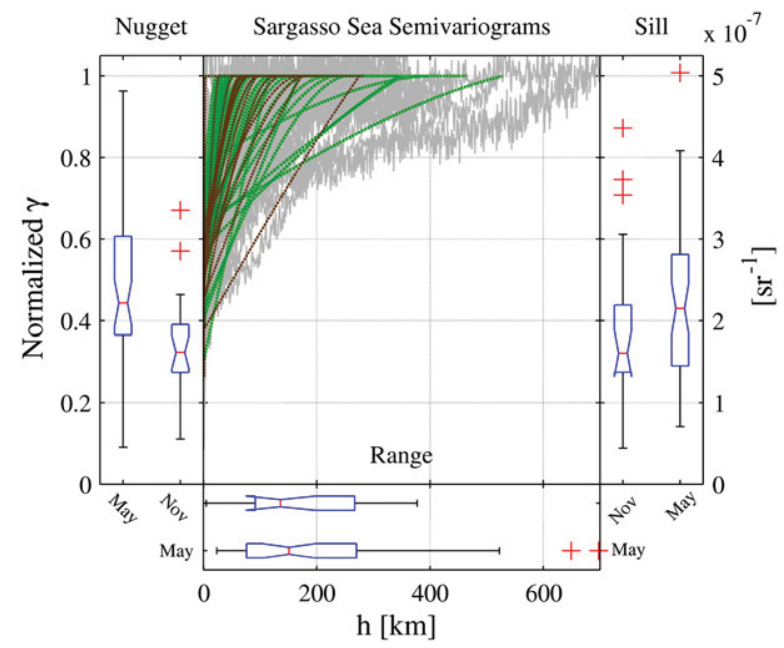

Fig. 10. Semivariograms and related parameters from HKM MODIS imagery at the offshore region in the Sargasso Sea (see Figs. 7 \& 8for descriptive details). Note the change in sill scale between Figs. 7 and 8, and 9.

providing detailed on-orbit characterization of detector-specific noise levels. Thanks to all those from OBPG and elsewhere who advised via the NASA Ocean Color forum, particularly Sean Bailey and Gerhard Meister. Funding was provided by the NASA GEO-CAPE mission pre-formulation activity.

\section{References}

Ahmad, Z., Franz, B. A., McClain, C. R., Kwiatkowska, E. J., Werdell, J., Shettle, E. P., et al (2010). New aerosol models for the retrieval of aerosol optical thickness and normalized water-leaving radiances from the SeaWiFS and MODIS sensors over coastal regions and open oceans. Applied Optics, 49, 5545-5560.

Atkinson, P. M., \& Curran, P. J. (1997). Choosing and appropriate spatial resolution for remote sensing investigations. Photogrammetric Engineering and Remote Sensing, $63,1345-1351$.

Babin, M., Morel, A., Fournier-Sicre, V., Fell, F., \& Stramski, D. (2003). Light scattering properties of marine particles in coastal and open ocean waters as related to the particle mass concentration. Limnology and Oceanography, 48, 843-859.

Bailey, S. W., Franz, B. A., \& Werdell, P. J. (2010). Estimation of near-infrared water-leaving reflectance for satellite ocean color data processing. Optics Express, 18, 7521-7527.

Beardsley, R. C., Limeburner, R., Yu, H., \& Cannon, G. A. (1985). Discharge of the Changjiang (Yangtze River) into the East China Sea. Continental Shelf Research, 4, 57-76.

Bissett, W. P., Arnone, R. A., Davis, C. O., Dickey, T. D., Dye, D., Kohler, D. D. R., et al. (2004). From meters to kilometers. Oceanography, 17, 32-42.

Davis, C. O., Kavanaugh, M., Letelier, R., Bissett, W. P., \& Kohler, D. D. R. (2007). Spatia and spectral resolution considerations for imaging coastal waters. In R. J. Frouin, \& Z. P. Lee (Eds.), Coastal Ocean Remote Sensing: Proc. of SPIE.

Dickey, T., Lewis, M., \& Chang, G. (2006). Optical oceanography: Recent advances and future directions using global remote sensing and in situ observations. Reviews of Geophysics, 44, RG1001.

Doney, S. E., Glover, D. M., McCue, S. J., \& Fuentes, M. (2003). Mesoscale variability of Sea-viewing Wide Field-of-view Sensor (SeaWiFS) satellite ocean color: Global patters and spatial scales. Journal of Geophysical Research, 108.

Fishman, J., Iraci, L., Al-Saadi, J., Chance, K., Chavez, F., Chin, M., Coble, P., Davis, C., DiGiacomo, P., \& Edwards, D. (2012). The United States' Next Generation of Atmospheric Composition and Coastal Ecosystem Measurements: NASA's Geostationary Coastal and Air Pollution Events (GEO-CAPE) Mission. Bulletin of the American Meteorological Society, 93, 1547-1566.

Gellis, A. C., Banks, W. S. L., Langland, M. J., \& Martucci, S. K. (2005). Summary of suspended-sediment data for streams draining the Chesapeake Bay Watershed, water years 1952-2002. In U.S.G. Survey (Ed.), Scientific Investigation Report 2004-5056. USGS.
Gordon, H. R., \& Wang, M. (1994). Retrieval of water-leaving radiance and aerosol optical thickness over the oceans with SeaWiFS: A preliminary algorithm. Applied Optics, 33, 443-452.

Guyot, J. L., Callede, J., Molinier, M., Guimaraes, V., \& Oliveira, E. D. (1997). La variabilité hydrologique actuelle dans le bassin de l'Amazone. Bulletin de l'Institut Francais d'Études Andines, 27.

Harding, L. W., Itsweire, E. C., \& Esaias, W. E. (1994). Estimates of phytoplankton biomass in the Chesapeake Bay from aircraft remote sensing of chlorophyll concentrations, 1989-92. Remote Sensing of Environment, 49, 41-56.

Hu, C., Feng, L., Lee, Z., Davis, C. O., Mannino, A., McClain, C. R., et al. (2012). Dynamic range and sensitivity requirements of satellite ocean color sensors: Learning from the past. Applied Optics, 51, 6045-6062.

Hu, C., Montgomery, E. T., Schmitt, R. W., \& Muller-Karger, F. E. (2004). The dispersal of the Amazon and Orinoco River water in the tropical Atlantic and Caribbean Sea: Observation from space and S-PALACE floats. Deep Sea Research Part II: Topical Studies in Oceanography, 51, 1151-1171.

Hu, C., Nelson, J. R., Johns, E., Chen, Z., Weisberg, R. H., \& Müller-Karger, F. E. (2005). Mississippi River water in the Florida Straits and in the Gulf Stream off Georgia in summer 2004. Geophysical Research Letters, 32 (n/a-n/a).

Kirk, J. T. O. (1994). Light and photosynthesis in aquatic ecosystems (2nd ed.)New York, NY: Cambridge University Press.

Lee, Z., Hu, C., Arnone, R., \& Liu, Z. (2012). Impact of sub-pixel variations on ocean color remote sensing products. Optics Express, 20, 20844-20854.

Miller, R. L., \& McKee, B. A. (2004). Using MODIS Terra 250 m imagery to map concentrations of total suspended matter in coastal waters. Remote Sensing of Environment, 93, 259-266.

Milliman, J. D., Huang-ting, S., Zuo-sheng, Y. H., \& Mead, R. (1985). Transport and deposition of river sediment in the Changjiang estuary and adjacent continental shelf. Continental Shelf Research, 4, 37-45.

Milliman, J. D., \& Meade, R. H. (1983). World-wide delivery of river sediment to the Oceans. Journal of Geology, 91, 1-21.

Molinier, M., Ronchail, J., Guyot, J. L., Cochonneau, G., Guimaraes, V., \& de Oliveira, E. (2009). Hydrological variability in the Amazon drainage basin and African tropical basins. Hydrological Processes, 23, 3245-3252.

Molleri, G. S., Novo, E. M. d. M., \& Kampel, M. (2010). Space-time variability of the Amazon River plume based on satellite ocean color. Continental Shelf Research, 30, 342-352.

Moreira-Turcq, P., Seyler, P., Guyot, J. L., \& Etcheber, H. (2003). Exportation of organic carbon from the Amazon River and its main tributaries. Hydrological Processes, $17,1329-1344$.

Ondrusek, M., Stengel, E., Kinkade, C. S., Vogel, R. L., Keegstra, P., Hunter, C., \& Kim, C. (2012). The development of a new optical total suspended material algorithm for the Chesapeake Bay. Remote Sensing of Environment, 119, 243-254.

Rabalais, N., Turner, R. E., Justić, D., Dortch, Q., Wiseman, W., \& Sen Gupta, B. (1996). Nutrient changes in the Mississippi River and system responses on the adjacent continental shelf. Estuaries, 19, 386-407.

Ruddick, K. G., Ovidio, F., \& Rijkeboer, M. (2000). Atmospheric correction of SeaWiFS imagery for turbid coastal and inland waters. Applied Optics, 39, 897-912.

Ruddick, K., Vanhellemont, Q., Yan, J., Neukermans, G., Wei, G., \& Shang, S. (2012). Variability of suspended particulate matter in the Bohai Sea from the geostationary Ocean Color Imager (GOCI). Ocean Science Journal, 47, 331-345.

Shi, W., \& Wang, M. (2009a). An assessment of the black ocean pixel assumption for MODIS SWIR bands. Remote Sensing of Environment, 113, 1587-1597.

Shi, W., \& Wang, M. (2009b). Satellite observations of flood-driven Mississippi River plume in the spring of 2008. Geophysical Research Letters, 36, 1-5.

Shi, W., \& Wang, M. (2010). Satellite observations of the seasonal sediment plume in central East China Sea. Journal of Marine Systems, 82, 280-285.

Wang, M., \& Shi, W. (2006). Cloud masking for ocean color data processing in coastal regions. IEEE Transactions on Geoscience and Remote Sensing, 44, 3196-3205.

Wang, M., Son, S. H., \& Harding, L. W., Jr. (2009). Retrieval of diffuse attenuation coefficient in the Chesapeake Bay and turbid ocean regions for satellite ocean color applications. Journal of Geophysical Research, 114, C10-C011.

Wang, M., Son, S., \& Shi, W. (2010). Evaluation of MODIS SWIR and NIR-SWIR atmospheric correction algorithms using SeaBASS data. Remote Sensing of Environment, 113, 635-644.

Werdell, P. J., Franz, B. A., \& Bailey, S. W. (2010). Evaluation of shortwave infrared atmospheric correction for ocean color remote sensing of Chesapeake Bay. Remote Sensing of Environment, 114, 2238-2247.

Xiong, X., Sun, J., Barnes, W. L., \& Salomonson, V. V. (2010). On-orbit calibration and performance of Aqua MODIS reflective solar bands. IEEE Transactions on Geoscience and Remote Sensing, 48, 535-546.

Zeng, N. (1999). Seasonal cycle and interannual variability in the Amazon hydrologic cycle. Journal of Geophysical Research-Atmospheres, 104, 9097-9106. 